IZA DP No. 6580

Hard Evidence on Soft Skills

James J. Heckman

Tim Kautz

May 2012 


\title{
Hard Evidence on Soft Skills
}

\author{
James J. Heckman \\ University of Chicago, American Bar Foundation, \\ University College Dublin and IZA \\ Tim Kautz \\ University of Chicago
}

\section{Discussion Paper No. 6580 \\ May 2012}

\author{
IZA \\ P.O. Box 7240 \\ 53072 Bonn \\ Germany \\ Phone: +49-228-3894-0 \\ Fax: +49-228-3894-180 \\ E-mail: iza@iza.org
}

\begin{abstract}
Any opinions expressed here are those of the author(s) and not those of IZA. Research published in this series may include views on policy, but the institute itself takes no institutional policy positions.

The Institute for the Study of Labor (IZA) in Bonn is a local and virtual international research center and a place of communication between science, politics and business. IZA is an independent nonprofit organization supported by Deutsche Post Foundation. The center is associated with the University of Bonn and offers a stimulating research environment through its international network, workshops and conferences, data service, project support, research visits and doctoral program. IZA engages in (i) original and internationally competitive research in all fields of labor economics, (ii) development of policy concepts, and (iii) dissemination of research results and concepts to the interested public.
\end{abstract}

IZA Discussion Papers often represent preliminary work and are circulated to encourage discussion. Citation of such a paper should account for its provisional character. A revised version may be available directly from the author. 


\section{ABSTRACT}

\section{Hard Evidence on Soft Skills*}

This paper summarizes recent evidence on what achievement tests measure; how achievement tests relate to other measures of "cognitive ability" like IQ and grades; the important skills that achievement tests miss or mismeasure, and how much these skills matter in life. Achievement tests miss, or perhaps more accurately, do not adequately capture, soft skills - personality traits, goals, motivations, and preferences that are valued in the labor market, in school, and in many other domains. The larger message of this paper is that soft skills predict success in life, that they causally produce that success, and that programs that enhance soft skills have an important place in an effective portfolio of public policies.

JEL Classification: I20, D01

Keywords: personality, achievement tests, IQ, cognition

Corresponding author:

James J. Heckman

Department of Economics

University of Chicago

1126 E. 59th Street

Chicago, IL 60637

USA

E-mail: jjh@uchicago.edu

\footnotetext{
* This paper was presented as the Adam Smith Lecture at the Annual Meeting of the European Association of Labour Economists held in Cyprus, September 2011. This research was supported in part by the University of Chicago, A New Science of Virtues: A Project of the University of Chicago, the American Bar Foundation, a conference series from the Spencer Foundation, the JB \& MK Pritzker Family Foundation, Susan Thompson Buffett Foundation, the Geary Institute, University College Dublin, Ireland, NICHD R37 HD065072 and R01 HD054702, we acknowledge the support of a European Research Council grant hosted by University College Dublin, DEVHEALTH 269874, a grant to the Becker Friedman Institute for Research and Economics from the Institute for New Economic Thinking (INET), and an anonymous funder. The views expressed in this paper are those of the authors and not necessarily those of the funders or commentators mentioned here. We thank Linor Kiknadze for research assistance. Paul Devereux made helpful comments that are incorporated in this paper.
} 


\section{Contents}

\begin{tabular}{lll}
\hline 1 & Introduction & 2
\end{tabular}

$\begin{array}{|lll|}2 & \text { Defining and Measuring Personality Traits } & 7\end{array}$

$2.1 \quad$ History and Measurement of Cognitive Ability . . . . . . . . . . . . . . . . . 7

2.2 Defining and Measuring Psychological Traits . . . . . . . . . . . . . . . . . . 9

2.3 Identification Problems in Measuring Traits . . . . . . . . . . . . . . . . . . 14

2.4 Are There Stable Personality Traits? . . . . . . . . . . . . . . . . . . . . . 16

2.5 The Evolution of Personality Traits Over the Life Cycle . . . . . . . . . . . . 17

2.6 The Predictive Power of Personality . . . . . . . . . . . . . . . . . . . . . . 18

\begin{tabular}{lll}
\hline 3 & Causal Evidence & 20
\end{tabular}

3.1 Problems with Establishing Causality . . . . . . . . . . . . . . . . . . . . . . 20

3.2 Extreme Examples of Personality Change . . . . . . . . . . . . . . . . . . . 22

3.3 Evidence from the GED Testing Program . . . . . . . . . . . . . . . . . . . . 23

$3.4 \quad$ Evidence from The Perry Preschool Program and Other Interventions . . . . 32

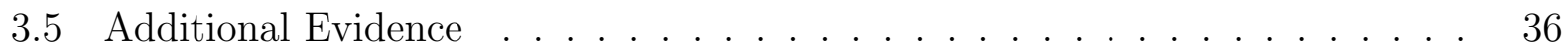

\begin{tabular}{|lll}
\hline 4 & Summary & 37
\end{tabular} 


\section{Introduction}

Contemporary society places great value on standardized achievement tests to sift and sort people, to evaluate schools, and to assess the performance of nations. Admissions committees use tests like the SAT (Scholastic Assessment Test), the ACT (American College Testing), and the GRE (Graduate Record Examinations) to screen applicants. In the United States, the No Child Left Behind (NCLB) Act stipulates that government-run schools must administer standardized achievement tests in order to be eligible for federal funding 11 The Programme for International Student Assessment (PISA) evaluates student performance in math, science, and reading across countries. The results attract media attention and influence policy. The year 2000 PISA test results caused Germany to re-evaluate its educational system and introduce a variety of educational reforms (Grek, 2009).

Despite the widespread use of standardized achievement tests, the traits that they measure are not well-understood. This paper summarizes recent evidence on what achievement tests capture; how achievement tests relate to other measures of "cognitive ability" like IQ and grades; the important skills that achievement tests miss or mismeasure, and how much these other skills matter in life.

Achievement tests miss, or more accurately, do not adequately capture, soft skillspersonality traits, goals, motivations, and preferences that are valued in the labor market, in school, and in many other domains. The larger message of this paper is that soft skills predict success in life, that they produce that success, and that programs that enhance soft skills have an important place in an effective portfolio of public policies.$^{2}$

Measurement of cognition and educational attainment has been refined during the past century. Psychometricians have shown that cognitive ability has multiple facets $3^{3}$ This

\footnotetext{
${ }^{1}$ Sales of achievement tests have increased by nearly $400 \%$ between 1959 and 2005 (Digest of Education Statistics, various years; The Bowker Annual: Library and Book Trade Almanac, various years). $(2012)$

${ }^{2}$ This paper draws on and supplements Borghans et al. (2008), Almlund et al. (2011), and Heckman et al.

${ }^{3}$ See Carroll (1994) and Ackerman and Heggestad (1997) for a discussion.
} 
progress is not widely appreciated. Many social scientists - even many psychologistscontinue to use IQ tests, standardized achievement tests, and grades interchangeably to proxy "cognitive ability." ${ }^{4}$ Even though scores on IQ tests, standardized achievement tests, and grades are positively correlated with each other, the recent literature shows that they measure different skills and depend on different facets of cognitive ability. Recent research also shows that all three measures are associated with personality, but to different degrees across various cognitive measures.

Standardized achievement tests were designed to capture "general knowledge" produced in schools and through life experiences. Such knowledge is thought to be relevant to success inside and outside of the classroom. However, achievement tests are often validated using other standardized achievement tests or other measures of cognitive ability - surely a circular practice.

A more relevant validity criterion is how well these tests predict meaningful outcomes, such as educational attainment, labor market success, crime, and health. No single measure of cognitive ability predicts much of the variance in these outcomes, and measurement error does not account for most of the remaining variance, leaving much room for other determinants of success 5

Success in life depends on personality traits that are not well captured by measures of cognition. Conscientiousness, perseverance, sociability, and curiosity matter. While economists have largely ignored these traits, personality psychologists have studied them over the last century. ${ }^{6}$ They have constructed measures of them and provide evidence that these traits predict meaningful life outcomes.

Many scholars - inside and outside of psychology — have questioned the existence of stable personality traits, arguing that constraints and incentives in situations almost entirely de-

\footnotetext{
${ }^{4}$ Many call this "IQ", e.g., Flynn (2007), Nisbett (2009), and Nisbett et al. (2012).

${ }^{5}$ On the magnitudes of measurement error on a variety of economic measures, see Bound et al. (2001). These authors report that at most $15-30 \%$ of earnings variance is due to measurement error.

${ }^{6}$ Some early studies in economics are Bowles and Gintis (1976), and Bowles et al. (2001). An important study in sociology is Jencks $(1979)$. Work in psychology going back to Terman et al. (1925) shows that personality traits matter (see Murray, 1938, Terman et al., 1947, and the discussion in Gensowski, 2012).
} 
termine behavior. These scholars claim that people are like chameleons - they are what they are shaped to be in any situation $\sqrt[7]{7}$ A substantial body of evidence shows that stable traits exist. People tend to behave in the same fashion across a wide range of situations 8 Evidence from genetics and neuroscience provides a biological basis for the existence of such traits, suggesting that something tied to the person, not the just the situation, affects behavior $9^{9}$

Throughout this paper we use the term "personality traits" to describe the personal attributes not thought to be captured by measures of abstract reasoning power. These attributes go by many names in the literature, including soft skills, personality traits, noncognitive skills, non-cognitive abilities, character, and socio-emotional skills. These different names connote different properties. The term "traits" suggests a sense of permanence and possibly also of heritability. The terms "skills" and "character" suggest that they can be learned. In reality, the extent to which these personal attributes can change lies on a spectrum. Both cognitive and personality traits can change and be changed over the life cycle but through different mechanisms and to different degrees at different ages. To avoid confusion, throughout this paper we use the term "trait" to capture the set of personal attributes we study.

Psychological traits are not directly observed. There is no ruler for perseverance, no caliper for intelligence. All cognitive and personality traits are measured using performance on "tasks," broadly defined. Different tasks require different traits in different combinations. Some distinguish between measurements of traits and measurements of outcomes, but this distinction is misleading. Both traits and outcomes are measured using performance on some task or set of tasks.

Psychologists sometimes claim to circumvent this measurement issue by creating tax-

\footnotetext{
${ }^{7}$ See Mischel (1968). Some behavioral economists share this view. See, e.g., Thaler (2008).

${ }^{8}$ See Epstein (1979) for an early paper showing that personality traits are stable across multiple situations. See the special issue of Journal of Research in Personality (43), "Personality and Assessment at Age 40." for a more recent discussion.

${ }^{9}$ See Bouchard and Loehlin (2001) for estimates of the heritability of traits. See Canli (2006) and DeYoung et al. (2010) for evidence that regions of the brain are associated with different traits.

${ }^{10}$ Drawing on the literature in psychology, Borghans et al. (2008) present one definition of cognitive traits.
} 
onomies of traits and by applying intuitive names to responses on questionnaires. These questionnaires are not windows to the soul. They are still rooted in task performance or behavior. Responding to a questionnaire is a task. Many of the questionnaires inquire directly about behavior, e.g. a measure of Agreeableness used in the German Socioeconomic Panel asks the extent to which a respondent "is sometimes somewhat rude to others." How else can one answer that question but reflect on one's behavior? IQ tests and standardized achievement tests also measure performance on different "cognitively loaded" tasks.

Performance on most tasks depends on effort, personality traits, cognitive ability, and incentives, although the importance of each differs by task. This dependence creates a fundamental problem in measuring traits. Most studies in psychology devise a set of measures to capture a trait but do not standardize for incentives in the situation in which the trait is being measured or for other traits. Measured cognitive ability and measured personality depend on a constellation of factors. The identification problem arising from the multiple determinants of performance on tasks is empirically important, even for measures of cognitive ability. Incentives can affect performance on IQ tests. Multiple traits affect performance on cognitive tasks. For example, personality traits affect achievement test scores and grades. ${ }^{11}$ Caution is required in taking the measures developed by psychologists too literally.

Nonetheless, measures of personality traits predict meaningful life outcomes. Conscientiousness - the tendency to be organized, responsible, and hardworking - is the most widely predictive of the commonly used personality measures. It predicts educational attainment, health, and labor market outcomes as strongly as measures of cognitive ability. ${ }^{12}$

Most studies in psychology only report correlations between measured traits and outcomes without addressing whether the traits cause the outcomes and without controlling for the other traits and incentives that determine performance on the tasks used to measure the traits. While traits are relatively stable across situations, they are not set in stone. They change over the life cycle. On average, Agreeableness and Conscientiousness tend to grow

\footnotetext{
${ }^{11}$ See Borghans et al. (2011a).

${ }^{12}$ See the evidence collected in Almlund et al. (2011), Borghans et al. (2008), and Roberts et al. (2007).
} 
with age. Different facets of cognitive ability peak at different ages. Interventions, education, and parenting can affect traits in lasting ways.

This paper summarizes recent evidence that personality causally affects life outcomes. We review some of the literature from psychology and economics and then focus on two particularly compelling examples 13

First, we show how an achievement test, the General Educational Development (GED) test, fails to capture important traits that affect success in life. High school dropouts can take the GED to certify to employers and post-secondary institutions that their skills are equivalent to those of high school graduates who do not attend college. After accounting for differences in pre-existing cognitive ability, GED recipients perform much worse in the labor market than high school graduates and much more like other high school dropouts. GED recipients lack important personality traits. (See Heckman et al., 2011 and Heckman et al., 2012.)

Second, we show how an early childhood intervention, the Perry Preschool Program, improved the lives of disadvantaged children, even though the program did not permanently change the IQ of its participants. The program changed their personality traits in a lasting way. (See Heckman et al., 2012.) Other interventions and observational studies provide supporting evidence that early-childhood investments improve outcomes through their effects on personality: 14

\footnotetext{
${ }^{13}$ Borghans et al. (2008) and Almlund et al. (2011) present extensive surveys of this literature.

${ }^{14}$ The "Tools of the Mind" intervention is designed to promote "executive functioning," which has both cognitive and personality components. Barnett et al. (2008, 2006); Bierman et al. (2010); Bodrova and Leong (2001, 2007); Dee and West (2011); Diamond et al. (2007); Durlak et al. (2011); Lillard and ElseQuest (2006) report success of this intervention. For a contrary view, see the study by Farran and Wilson (2011).
} 


\section{Defining and Measuring Personality Traits}

\subsection{History and Measurement of Cognitive Ability}

Modern intelligence tests have been used for just over a century, beginning when a French minister of public instruction wished to identify retarded pupils in need of specialized education programs. In response, Alfred Binet created the first IQ test 15 IQ scores were interpreted as measuring a stable trait. The standardized achievement test was created in the wake of the perceived success of IQ tests as an objective and cost-effective measure of acquired skills. In contrast to IQ tests, standardized achievement tests were designed to measure "general knowledge" that could be acquired in schools and through life experiences and was widely applicable beyond the classroom to workplace and social functioning. ${ }^{16}$

Achievement tests are typically validated on other achievement tests, IQ tests, and grades, rather than on tasks or outcomes in the labor market and in social functioning. Table 1 shows correlations among scores on standardized achievement tests, IQ tests, and grades. Standardized achievement tests are correlated with IQ tests, but the correlation depends on the subject area of the standardized achievement test. Hartlage and Steele (1977) find that the arithmetic portions of standardized achievement tests are the most highly correlated with IQ. Grades and scores on IQ tests and standardized achievement tests are far from perfectly correlated, suggesting that they measure different aspects of "cognitive functioning." 17

Psychologists distinguish between fluid intelligence (the rate at which people learn) and crystalized intelligence (acquired knowledge) ${ }^{18}$ Achievement tests are heavily weighted to-

\footnotetext{
${ }^{15}$ In 1904, La Société Libre pour l'Etude Psychologique de l'Enfant appointed a commission to create a mechanism for identifying these pupils in need of alternative education led by Binet. See Herrnstein and Murray (1994) for an overview of Binet's life and work.

${ }^{10}$ See Lindquist (1951).

${ }^{17}$ It is an irony of the testing literature that high school grades are more predictive of first year college performance than SAT scores (Bowen et al., 2009). The SAT and related tests are thought to be more objective measures of student quality than high school grades (Lemann, 1999).

${ }^{18}$ See e.g. Nisbett et al. (2012).
} 
Table 1: Cognitive Ability Validities

\begin{tabular}{llll}
\hline Test & Validation Domain & Estimate(s) & Source(s) \\
\hline SAT (Achievement) & 1st Year College GPA & $0.35-0.53$ & Kobrin et al. (2008) \\
ACT (Achievement) & Early College GPA & 0.42 & ACT, Inc. (2007) \\
GED (Achievement) & HS Senior GPA & $0.33-0.49$ & GED Testing Service (2009) \\
DAT (Achievement) & College GPA & $0.13-0.62^{\dagger}$ & Omizo (1980) \\
AFQT (Achievement) & 9th Grade GPA & 0.54 & Borghans et al. (2011a) \\
WAIS (IQ) & College GPA & $0.38-0.43$ & Feingold 1982 \\
WAIS (IQ) & HS GPA & Feingold (1982) \\
Various IQ** & 9th Grade GPA & 0.42 & Borghans et al. (2011a) \\
WISC (IQ) & WRAT (Achievement) & $0.44-0.75^{\ddagger}$ & Hartlage and Steele (1977) \\
WISC-R (IQ) & WRAT (Achievement) & $0.35-0.76^{\ddagger}$ & Hartlage and Steele (1977) \\
Various IQ** & AFQT (Achievement) & 0.65 & Borghans et al. (2011a) \\
Stanford Binet (IQ) & WISC-R (IQ) & $0.77-0.87$ & Rothlisberg (1987), Greene et al. (1990) \\
Raven's (IQ) & WAIS-R (IQ) & $0.74-0.84$ & O'Leary et al. (1991) \\
WIAT (Achievement) & CAT/2 (Achievement) & $0.69-0.83^{*}$ & Michalko and Saklofske (1996) \\
\hline
\end{tabular}

Definitions: WISC - Wechsler Intelligence Scale for Children, WISC-R - Wechsler Intelligence Scale for Children - Revised, WAIS - Wechsler Adult Intelligence Scale, Raven's IQ - Raven's Standard Progressive Matrices, GED - General Educational Development, $\underline{\mathrm{DAT}}$ - Differential Aptitude Test, $\underline{\mathrm{WIAT}}$ - Wechsler Individual Achievement Test, $\underline{\mathrm{CAT}}$ - California Achievement Test, WRAT - Wide Range Achievement Test

$\dagger$ Large range is due to varying validity of eight subtests of DAT

$\ddagger$ Ranges are given because correlations vary by academic subject

* Ranges are given because correlations vary by grade level

** IQ test scores in the NLSY79 are pooled across several IQ tests using IQ percentiles 
wards crystallized intelligence 19 whereas IQ tests like Raven's progressive matrices (1962) are heavily weighted toward fluid intelligence ${ }^{20}{ }^{21}$ Many psychologists do not recognize the differences among these measures and interchangeably use IQ, achievement tests, and grades to measure "cognitive ability" or "intelligence," and this practice is also widespread in economics 22

\subsection{Defining and Measuring Psychological Traits}

Validating one measure of cognitive ability using other measures of cognitive ability is circular. More relevant is how well these measures predict important life outcomes. Table 2 shows the extent to which IQ, standardized achievement tests, and grades explain the variance of outcomes at age 35 in the National Longitudinal Survey of Youth, 1979 (NLSY79) data. The three groups of columns under each category show results for different sub-samples based on the availability of the different cognitive measures. For each category, the first column shows the explained variance using only the designated measure of cognitive ability ${ }^{23}$ Achievement tests and grades are more predictive than IQ. But none of these measures explains much of the variation of any outcome, leaving considerable room for other determinants. As noted in the introduction, it is unlikely that measurement error accounts for all of the remaining variance.

Personality is one missing ingredient. The second columns in each category preview our later discussion of the explanatory power of personality. They show the variance explained by measures of personality. ${ }^{24}$ In many cases, the variance explained by personality measures rivals that explained by measures of cognitive ability. The relative importance of person-

\footnotetext{
$\sqrt[19]{\text { Roberts et al. }(2000) .}$

${ }^{20}$ Raven et al. (1988). The high correlation between intelligence and achievement tests is in part due to the fact that both require cognitive ability and knowledge. Common developmental factors may affect both of these traits. Fluid intelligence promotes the acquisition of crystallized intelligence.

${ }^{21}$ Carroll (1994) and Ackerman and Heggestad (1997) discuss more disaggregated facets of cognitive ability.

${ }^{22}$ See Flynn (2007) and Nisbett et al. (2012). For examples in economics see Benjamin et al. (2006).

${ }^{23} \mathrm{See}$ Almlund et al. (2011) for a more complete array of outcomes in the format of Table 2 .

${ }^{24}$ They include measures of adolescent risky behavior, self-esteem and locus of control (the extent to which people feel they have control over their lives). For precise definitions of the measures used, see the notes to Table 2
} 
ality depends on the outcome. The third column for each sub-sample shows the variance explained when both the cognitive and personality measures are used as predictors. In many cases, including the measures of personality in a regression with cognitive measures explains additional variance. The correlations between the set of measures of personality and the measures of cognition are positive, but not especially strong (see the bottom row of each table). Each set of traits has an independent influence on the outcomes in the table.

Even though economists have largely ignored personality traits, the pioneers of the original IQ tests recognized their importance ${ }^{25}$ Alfred Binet the creator of the first IQ test (the Stanford-Binet test), noted that:

"[Success in school] ...admits of other things than intelligence; to succeed in his studies, one must have qualities which depend on attention, will, and character; for example a certain docility, a regularity of habits, and especially continuity of effort. A child, even if intelligent, will learn little in class if he never listens, if he spends his time in playing tricks, in giggling, in playing truant."

-(Binet and Simon, 1916, p. 254)

Since the middle of the 19th century, personality psychologists have studied these traits. One leading personality psychologist defines personality traits in the following way:

"Personality traits are the relatively enduring patterns of thoughts, feelings, and behaviors that reflect the tendency to respond in certain ways under certain circumstances." (Roberts, 2009, p. 140)

Personality traits are manifested through thoughts, feelings, and behaviors, and therefore, must be inferred from measures of performance on "tasks," broadly defined. Under this

\footnotetext{
${ }^{25}$ Lewis Terman, who created the Stanford-Binet test, even collected data on personality traits of a highability sample. In this sample, Conscientiousness is highly predictive of health and earnings (Savelyev, 2011. Gensowski, 2012).
} 


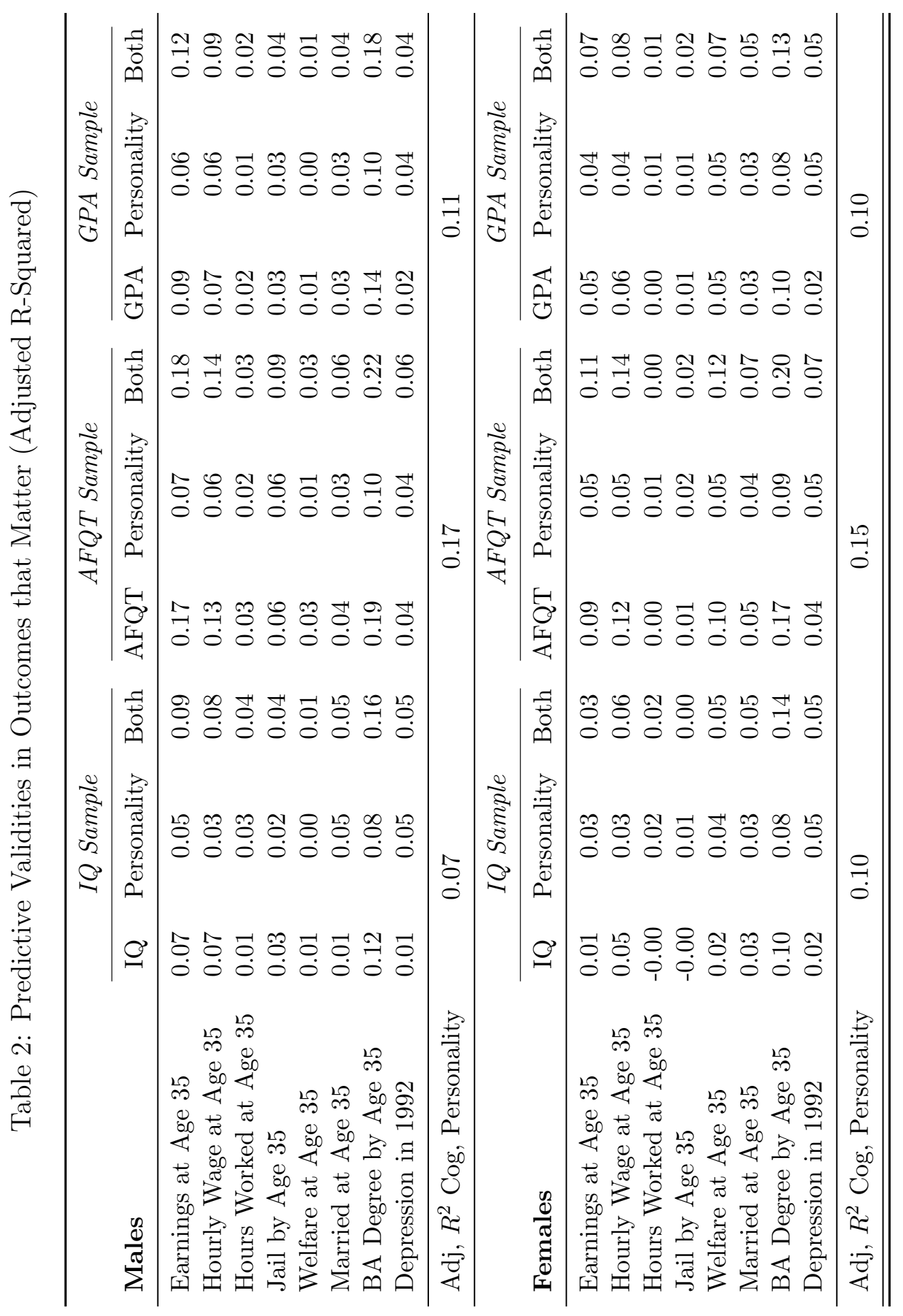

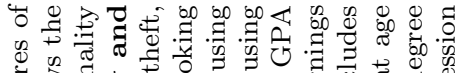

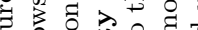

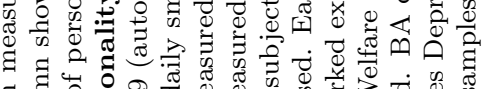

㐘

今

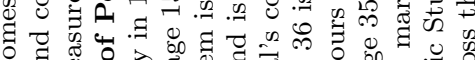

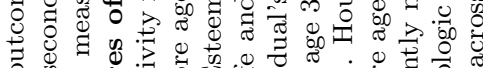

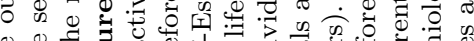

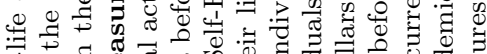

वे

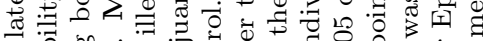

पे

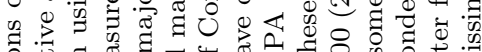

.

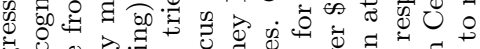

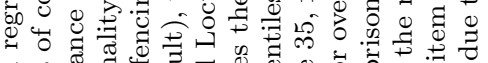

च 0 .

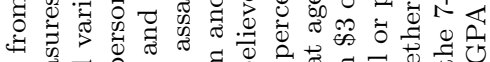

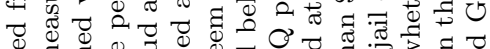

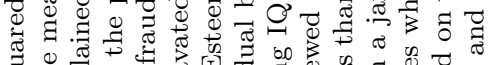

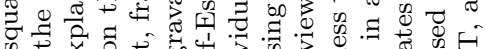

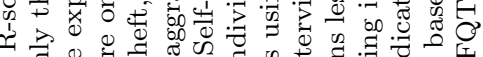

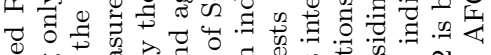

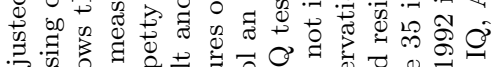

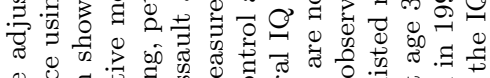

‡

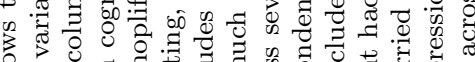

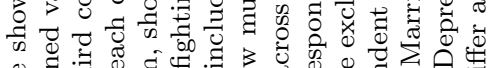

๑ : స

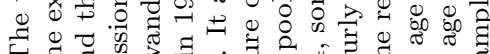

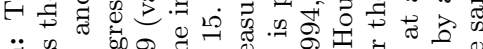

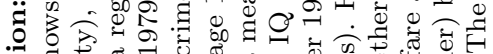

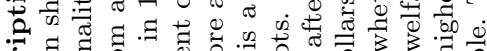

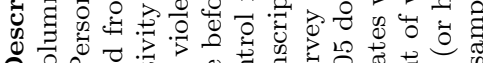

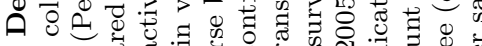

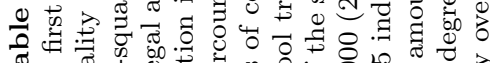

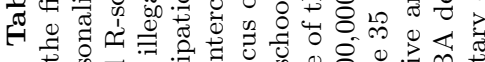
S.

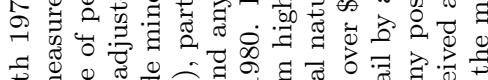

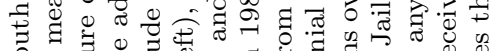

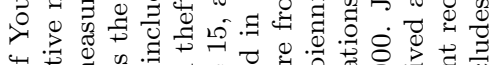

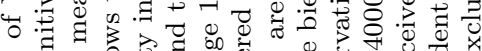

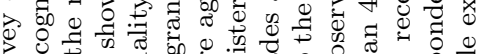

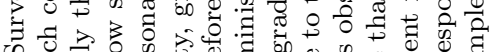
जी

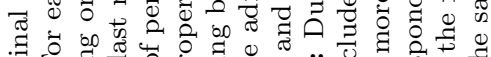

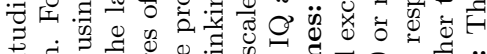

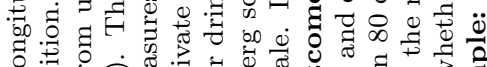

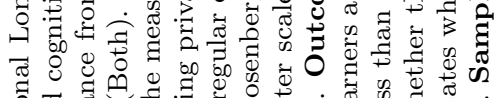

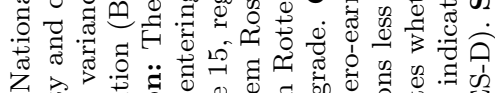
乙

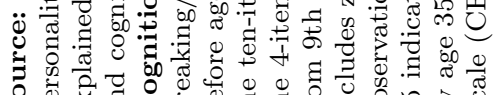

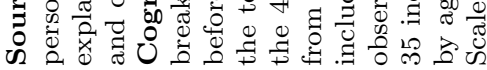


definition, performance on IQ tests is a personality trait because it is an enduring pattern of behavior (how one "behaves" or "performs" on an IQ test) ${ }^{26}$

Personality psychologists primarily measure personality traits using self-reported surveys. They have arrived at a relatively well-accepted taxonomy of traits called the "Big Five," which include Openness to Experience, Conscientiousness, Extraversion, Agreeableness, and Neuroticism. Table 3 defines these traits and their multiple facets ${ }^{27}$ Some argue that the Big Five are the longitude and latitude of personality, by which all more narrowly defined traits may be categorized (see Costa and McCrae, 1992a). While the Big Five measures are now the most widely used, there are several other taxonomies, including the Big Three, the MPQ, and the Big Nine. They are conceptually and empirically related to the Big Five ${ }^{28}$ Other taxonomies, including psychopathology as measured by the DSM IV and measures of temperament, have also been related to the Big Five ${ }^{29}$ Almlund et al. (2011) show that economic preference parameters are not all that closely related to psychological traits and apparently represent different traits that, along with the psychological traits, govern behavior.

A deeper issue, as yet not systematically investigated in the literature in economics or psychology, is whether the traits captured by the alternative measurement systems are the manifestation of a deeper set of preferences or goals. Achieving certain goals requires certain traits, e.g., a surgeon has to be conscientious and intelligent; a salesman has to be outgoing and engaging and so forth, etc. Under this view, traits are developed through practice, investment, and habituation. The deeper traits may be the preference parameters that generate the manifest traits. The apparent stability of expressed traits across situations may be a consequence of the stability of the goals and incentives to achieve these goals ${ }^{30}$

\footnotetext{
${ }^{26}$ Studies of test-retest reliability of IQ tests show that scores are highly correlated across repeated testing occasions (see, e.g., Niolon, 2005).

${ }^{27}$ See e.g. Borghans et al. $(2008)$.

${ }^{28}$ See Borghans et al. (2008) and Almlund et al. (2011) for a comparison of these taxonomies.

${ }^{29}$ See e.g Cloninger et al. (1999).

30 McAdams (2006) adds goals to the list of possible traits. Almlund et al. (2011) develop a model in which preferences and traits determine the effort applied to tasks.
} 

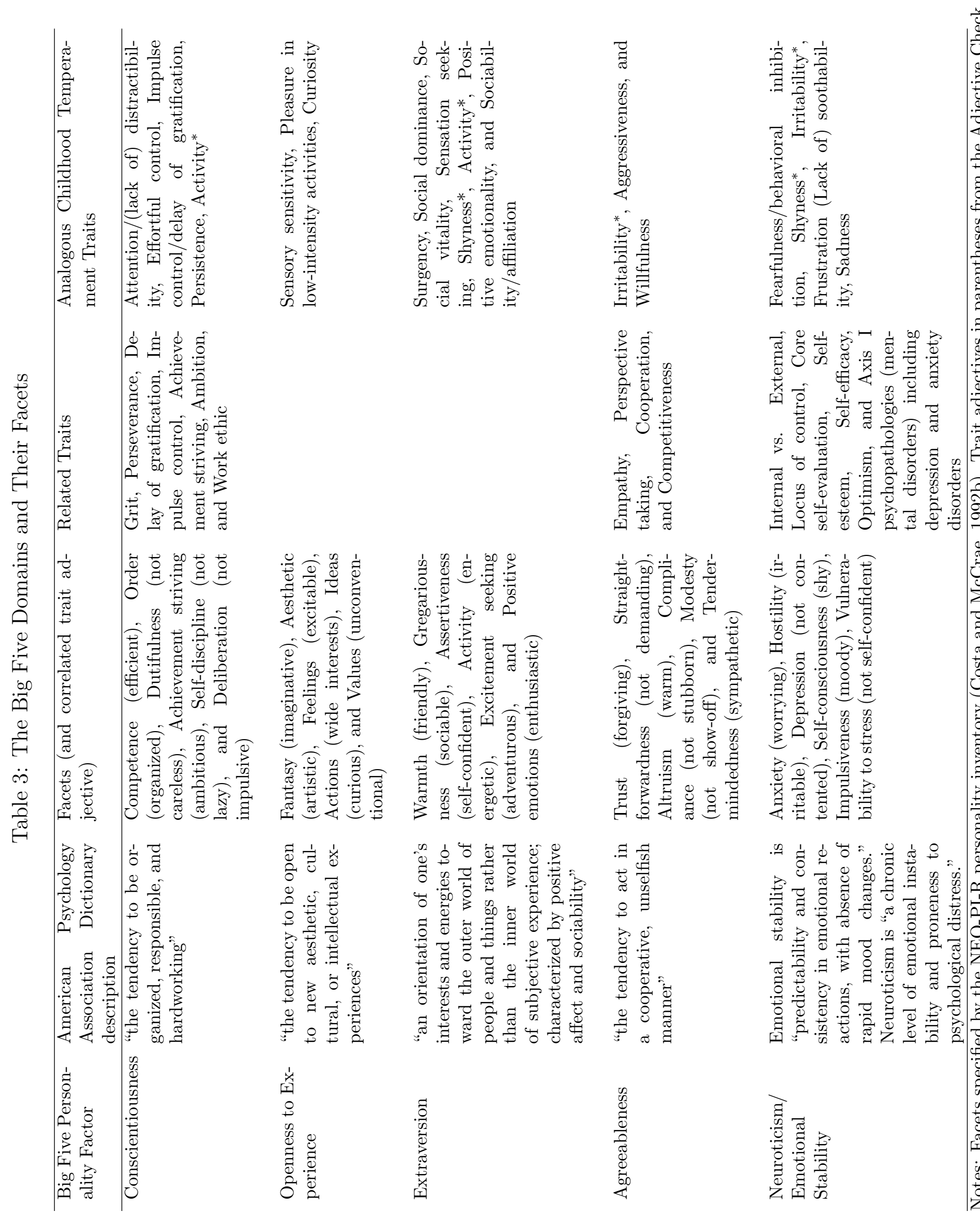

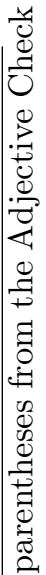
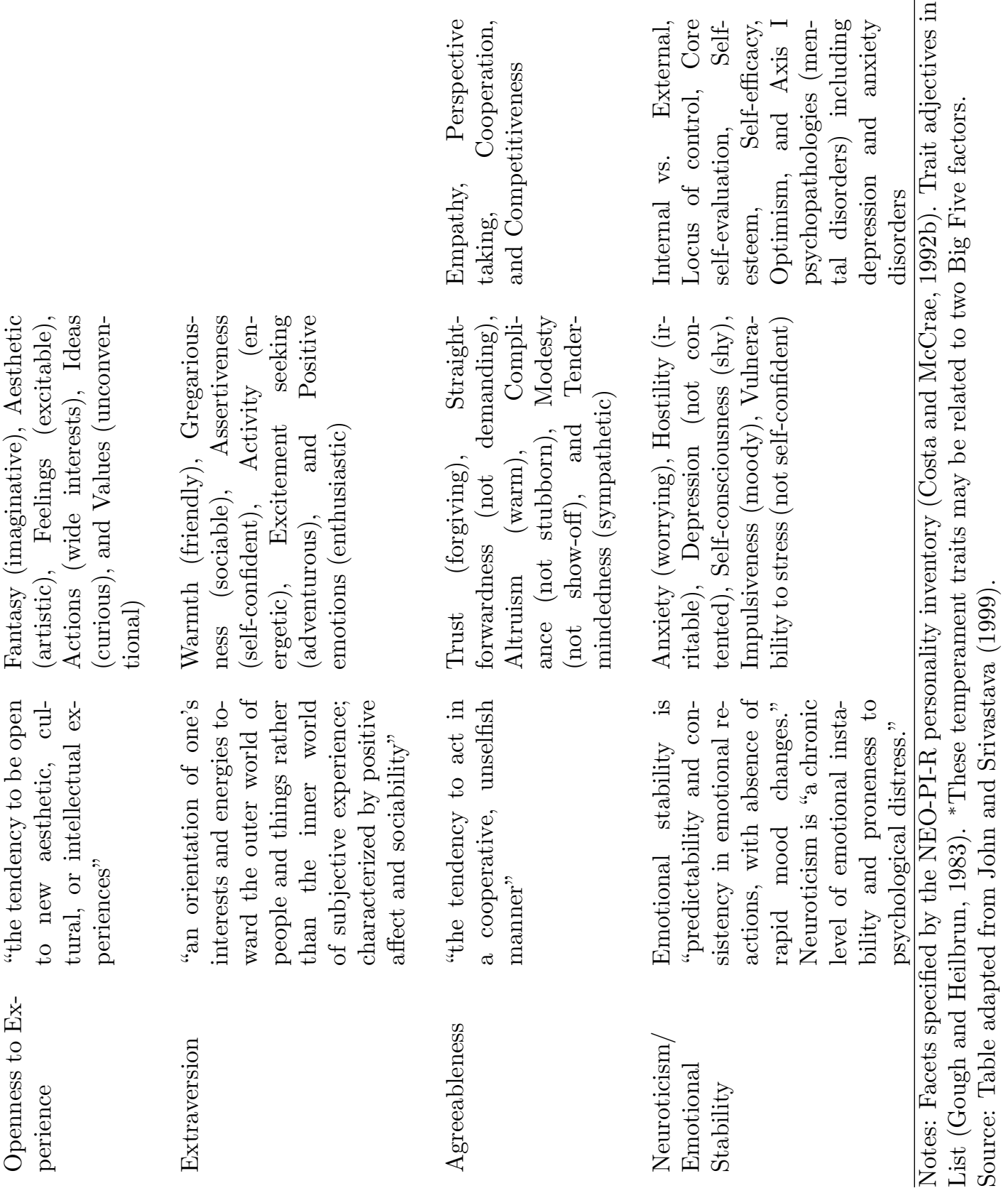

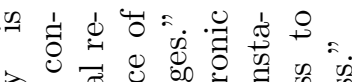

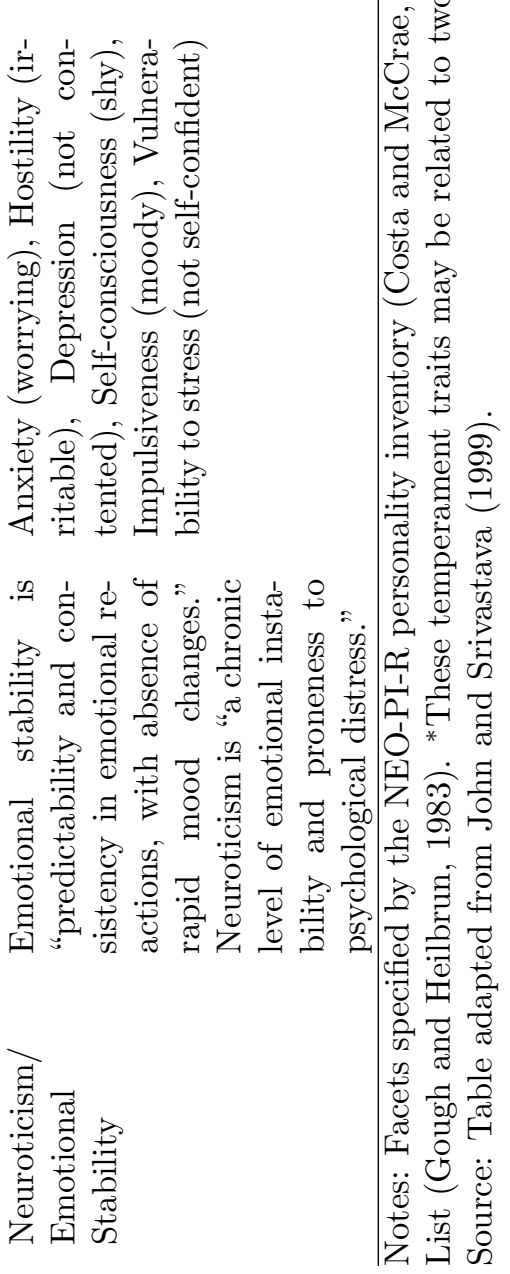

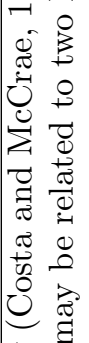

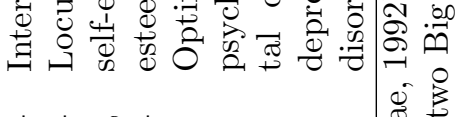




\subsection{Identification Problems in Measuring Traits}

Measuring traits is difficult, because, as suggested by Roberts' definition of personality, all psychological measurements are calibrated on measured behavior, and the behaviors used to measure one trait can be influenced by incentives and other traits. To infer traits from behaviors requires standardizing for all of the other contributing factors that produce the observed behavior. The inability to parse and localize behaviors that depend on a single trait or ability gives rise to a fundamental identification problem that is typically ignored in empirical research investigating how psychological traits affect outcomes 41

There are two primary issues. First, behavior depends on incentives created in situations. Different incentives elicit different amounts of effort on the tasks used to measure traits. Accurately measuring personality traits requires standardizing for the effort applied in any task. Second, behavior in one task can depend on multiple traits. Not standardizing for incentives and other traits can produce misleading estimates of any trait.

These identification problems are empirically important when measuring any given trait. For example, incentives partly determine scores on IQ tests, even though some have argued that performance on IQ tests reflects maximal effort.22 A series of studies conducted over the past 40 years show that incentives, like money or candy, can increase IQ scores, particularly among low-IQ individuals. The Black-White gap in IQ can be completely eliminated by incentivizing students with M\&M candies.33 The incentives in one test do not affect performance on future tests.

The recent literature shows that personality traits are associated with standardized achievement test scores, which many analysts use interchangeably with IQ scores ${ }^{34}$ Figures 1 and 2 show how the variance in the scores on two achievement tests, the Armed

\footnotetext{
${ }^{31}$ See Borghans et al. (2011a) and Almlund et al. (2011).

${ }^{32}$ A leading psychometrician, Carroll (1993), does not accept the notion that IQ captures maximal effort.

${ }^{33}$ See Ayllon and Kelly (1972); Borghans et al. (2008); Breuning and Zella (1978); Clingman and Fowler (1976); Edlund (1972); Holt and Hobbs (1979); Larson et al. (1994); Segal (2008). This evidence is summarized in Borghans et al. (2008) and Almlund et al. (2011).

${ }^{34}$ See e.g. Nisbett (2009).
} 
Forces Qualifying Test (AFQT) and the closely related Differential Aptitudes Test (DAT) ${ }^{35}$ are decomposed into IQ and personality measures. Personality traits explain a substantial portion of the variances in both AFQT scores and DAT scores 36 The personality traits are incrementally valid in that they explain the variance above and beyond the variance that IQ explains when all three are included in a regression. These findings caution the interpretation that standardized achievement tests only measure cognitive ability. They are bundled with personality traits. In data from the Stella Maris secondary school in Maastricht, Holland, Openness to Experience is strongly correlated with IQ. ${ }^{37}$

Figure 1: Decomposing Achievement Tests and Grades into IQ and Personality [NLSY79]

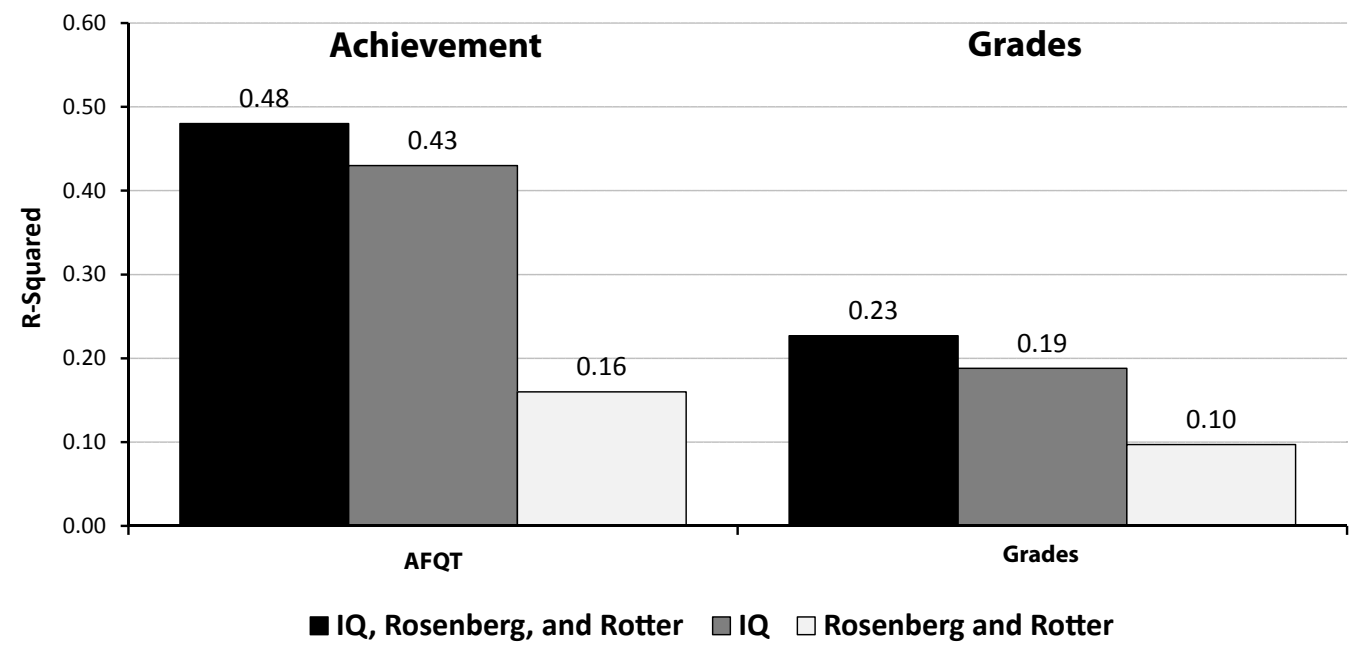

Source: Borghans et al. (2011a). Notes: Rotter was administered 1979. The ASVAB and Rosenberg were administered in 1980. AFQT is constructed from the Arithmetic Reasoning, Word Knowledge, Mathematical Knowledge, and Paragraph Comprehension ASVAB subtests. IQ and GPA are from high school transcript data. AFQT, Rosenberg, and Rotter have been adjusted for schooling at the time of the test conditional on final schooling, as laid out in Hansen et al. (2004). IQ is pooled across several IQ tests using IQ percentiles. GPA is the individual's core subject GPA from 9th grade. Sample excludes the military over-sample.

Further complicating identification, not everyone responds to incentives in the same way.

\footnotetext{
${ }^{35}$ The correlation between DAT and AFQT scores in the National Longitudinal Study of Youth 1979 (NLSY79) is 0.76 to 0.80 (Borghans et al., 2011b). Friedman and Streicher (1985) estimate correlations between 0.65 and 0.82 for in a sample of high school sophomores and juniors. Kettner (1976) estimates correlations between DAT and the AFQT subtests of 0.76 to 0.89 in a sample of juniors and seniors.

${ }^{36}$ The lower explained variance in the sample with DAT is likely a consequence of restriction on range. The DAT data come from a single school, whereas the AFQT data come from a national sample.

${ }^{37}$ See Borghans et al. (2011b) for information on the Stella Marris secondary school and the analysis described in the text.
} 
Figure 2: Decomposing Achievement Tests and Grades into IQ and Personality [Stella Maris]

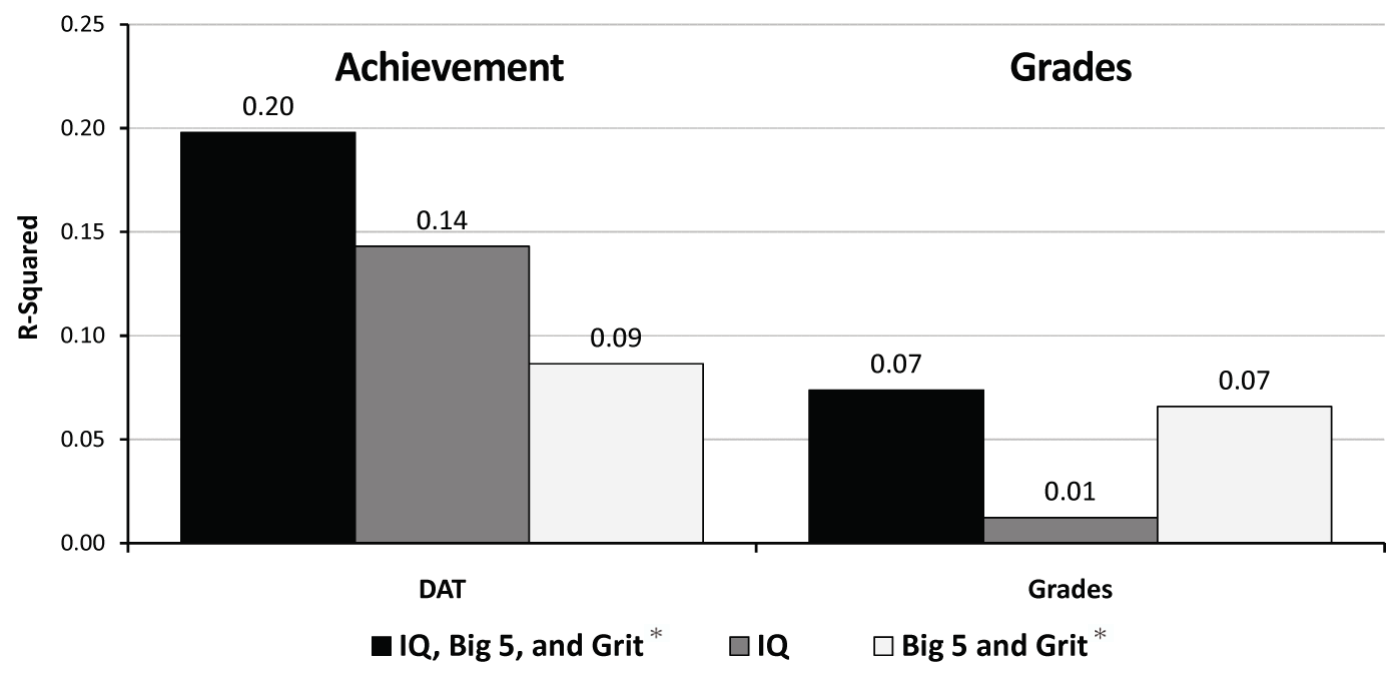

${ }^{*}$ Grit is a measure of persistence on tasks (Duckworth et al. 2007).

Source: Borghans et al. 2011a).

Borghans et al. (2008) show that adults spend substantially more time answering questions on IQ tests when rewards are higher. Subjects high in Emotional Stability and Conscientiousness are less affected by rewards. Similarly, Segal (2008) shows that introducing cash incentives for performance on the coding speed test of the Armed Services Vocational Battery (ASVAB) increases performance substantially, particularly for men with lower levels of Conscientiousness.

\subsection{Are There Stable Personality Traits?}

Many have questioned whether personality traits exist. The publication of Walter Mischel's 1968 book, Personality and Assessment, gave rise to a heated "personality-situation" debate within psychology, which pitted the social psychologists who favored situational factors as explaining behavior against those who considered stable personality traits as more consequential. Mischel argued that aspects of situations overshadow any effect of personality on 
behavior 38

A large body of evidence reviewed in Almlund et al. (2011) shows that stable personality traits exist and are predictive of many behaviors ${ }^{39}$ An important paper by Epstein (1979) presents compelling evidence that, averaging over tasks and situations at a point in time, people act in a predictable fashion with a high level of reliability ( $R^{2}$ of $\left.0.6-0.8\right)$ of average behavior ("measured personality") across situations. The incentives in any situation also matter. Heritability studies show that measures of personality traits tend to be about $40 \%$ $60 \%$ heritable, suggesting that something tied to the person, rather than the situation, influences behavior (Bouchard and Loehlin, 2001) $)^{40}$ Evidence in neuroscience suggests that expression of traits is related to regions of the brain (see Canli, 2006, and DeYoung et al., 2010 .

\subsection{The Evolution of Personality Traits Over the Life Cycle}

Even though personality traits are relatively stable across situations, they are not set in stone. They change over the life cycle. Figure 3 shows that Conscientiousness tends to increase monotonically over the life cycle. Other traits change in different ways over the life cycle 41 Crystallized intelligence tends to increase monotonically for most of the life cycle, whereas fluid intelligence tends to peak in early adulthood and then decline ${ }^{42}$

This evidence does not address whether these changes occur naturally ("ontogenic change") or whether they are due to changes in the environments commonly experienced over the life cycle ("sociogenic change"). No evidence is available in the published literature on the distributions of these profiles over the life cycle. Almlund et al. (2011) review the evidence on

\footnotetext{
${ }^{38}$ This theme has been picked up in behavioral economics. See Thaler $(2008)$.

${ }^{39}$ See the special issue of Journal of Research in Personality (43), entitled "Personality and Assessment at Age 40" for a recent discussion.

40 Devlin et al. (1997) suggest that traditional estimates of the heritability of IQ may be inflated because they fail to take into account the effect of the environment on conditions in the maternal womb. See also (Rutter, 2006) and an emerging literature on epigenetics.

${ }^{4 i}$ See the evidence collected in Borghans et al. (2008) and Almlund et al. (2011) for a variety of other traits.

${ }^{42}$ McArdle et al. (2000).
} 
how parental investment and interventions promote changes in personality.

Figure 3: Cumulative Mean-Level Changes in Personality Across the Life Cycle

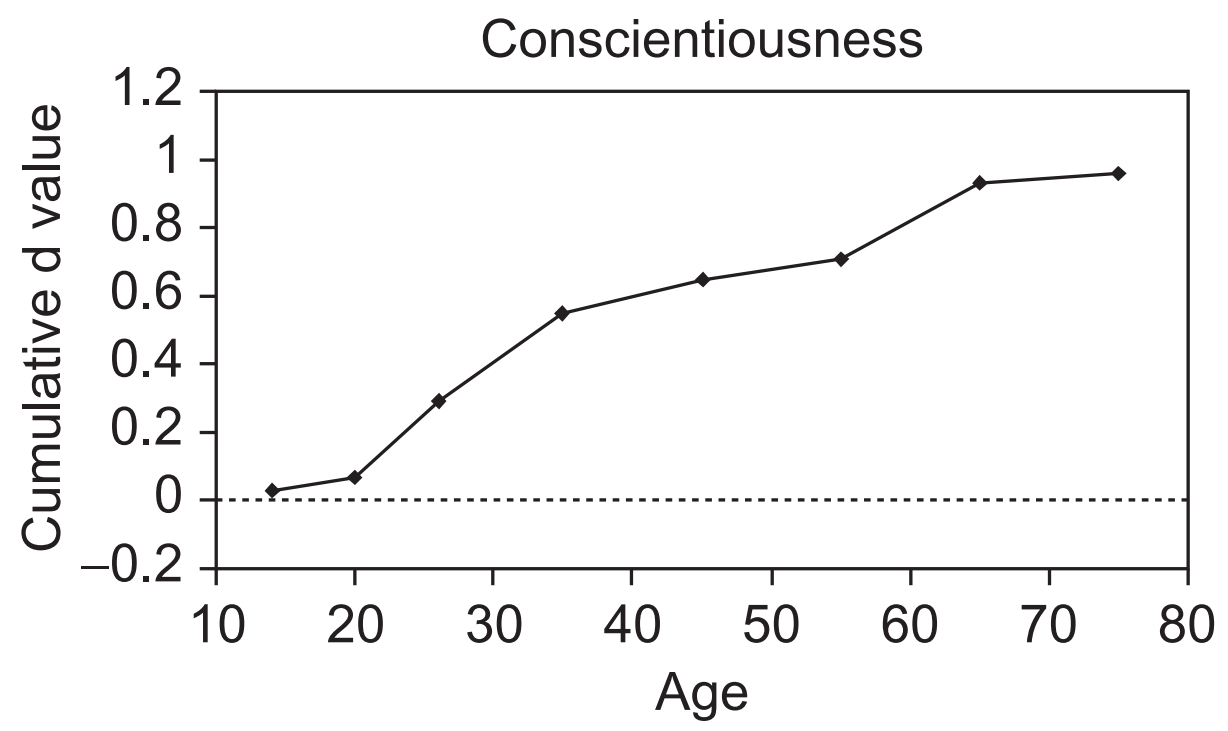

Note: Cumulative d values represent total lifetime change in units of standard deviations ("effect sizes").

Source: Figure taken from Roberts et al. (2006) and Roberts and Mroczek (2008). Reprinted with permission of the authors.

\subsection{The Predictive Power of Personality}

Table 2 shows that personality traits predict many later-life outcomes as strongly as measures of cognitive ability. Conscientiousness - the tendency to be perseverant and hardworking - stands out as the most predictive of the Big Five traits across many outcomes. Figure 4 presents for males correlations between the Big Five and educational attainment, adjusting and not adjusting for fluid and crystalized intelligence. Conscientiousness predicts educational attainment more than either of the facets of intelligence ${ }^{43}$ Similar patterns appear for many other outcomes, including labor market performance, grades, and health 44

A recurrent finding in the literature is that measured IQ is highly predictive of performance on complex tasks and jobs (Gottfredson, 1997). The importance of IQ increases with

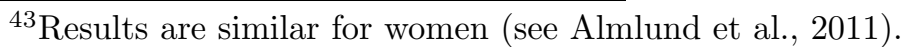

${ }^{44}$ See Almlund et al. (2011), Borghans et al. (2008), and Roberts et al. (2007) for comprehensive reviews of the evidence.
} 
job complexity, defined as the information processing requirements of the job: cognitive skills are more important for professors, scientists, and senior managers than for semi-skilled or unskilled laborers (Schmidt and Hunter, 2004). In contrast, the importance of Conscientiousness does not vary much with job complexity (Barrick and Mount, 1991), suggesting that it pertains to a wider spectrum of jobs.

The literature in economics establishes that the same bundle of traits has different productivity in different tasks. People also differ in their endowments of traits. These two features lead to sorting in the tasks people pursue in life and are a manifestation of the general principle of comparative advantage in the labor market and in life. (See Almlund et al., 2011, Borghans et al., 2008; Cattan, 2012, Heckman et al., 2006, 2011.)

Achievement test scores are crude, low-dimensional summaries of high-dimensional vectors of traits operating in conjunction with effort. It is unlikely that these summaries capture the precise combinations of traits required for success in specific life tasks. The thrust of recent research in personality and economics is to isolate the traits that determine life outcomes and to understand how those diverse traits determine choices of tasks.

Most of the evidence in personality psychology is correlational. The reported correlations do not prove that personality traits cause higher educational attainment although it is consistent with it. For example, the reported pattern in Table 4 could arise if educational attainment increased Conscientiousness. We next present causal evidence. 
Figure 4: Association of the Big Five and intelligence with years of completed schooling

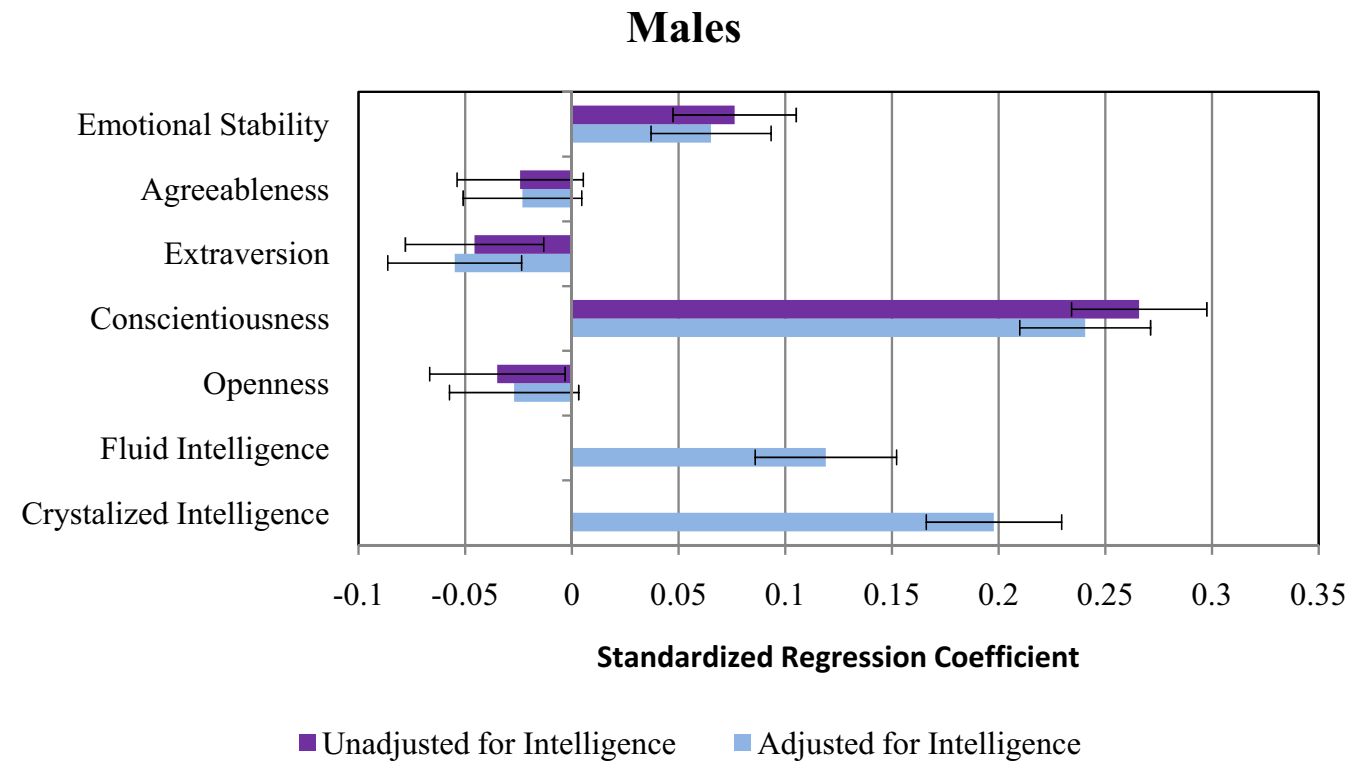

Notes: The figure displays standardized regression coefficients from a multivariate regression of years of school attended on the Big Five and intelligence, controlling for age and age squared. The bars represent standard errors. The Big Five coefficients are corrected for attenuation bias. The Big Five were measured in 2005. Years of schooling were measured in 2008. Intelligence was measured in 2006. The measures of intelligence were based on components of the Wechsler Adult Intelligence Scale (WAIS). The data is a representative sample of German adults between the ages 21 and 94 .

Source: Almlund et al. (2011) German Socio-Economic Panel (GSOEP), waves 20042008.

\section{Causal Evidence}

\subsection{Problems with Establishing Causality}

Most studies in personality psychology do not address the question of causality, i.e., whether measured traits cause (rather than just predict) outcomes. Empirical associations are not a reliable basis for policy analysis. In this section, we discuss difficulties in establishing causality. We also summarize several studies that provide evidence that personality traits cause outcomes.

We introduce a simple framework to analyze the effect of traits on outcomes and how traits evolve over time ${ }^{45}$ Equation (1) shows how an outcome at age $a, T_{a}$, which is the

\footnotetext{
${ }^{45}$ This framework draws on Almlund et al. (2011).
} 
performance on a task, depends on cognition $C_{a}$, personality $P_{a}$, other acquired skills such as education and job training $K_{a}$, and the effort allocated to the task $e_{T_{a}}$ :

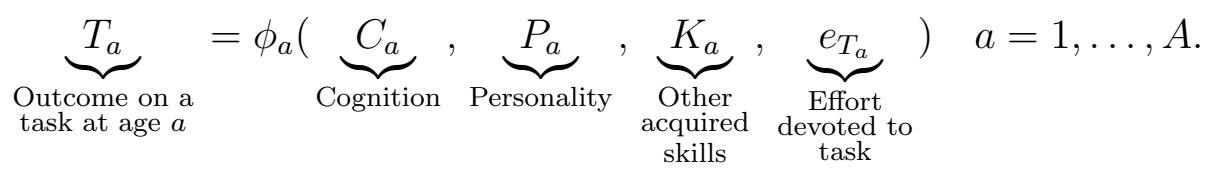

Equation (2) shows how the effort allocated to task $T_{a}$ depends on cognition $C_{a}$, personality $P_{a}$, other acquired skills $K_{a}$, incentives $R_{T_{a}}$, and preferences $\Upsilon_{a}$ :

$$
e_{T_{a}}=\psi_{T_{a}}(C_{a}, P_{a}, K_{a}, \underbrace{R_{T_{a}}}_{\begin{array}{c}
\text { Incentives } \\
\text { to perform } \\
\text { on task }
\end{array}}, \underbrace{\Upsilon_{a}}_{\text {Preferences }}) \underbrace{46}
$$

The effort applied to a task is the outcome of a choice problem that depends on traits, preferences, and incentives, much like a supply equation in the standard theory of consumer choice. Preferences can be thought of as additional traits. Some psychological theories posit that people have limited effort that they can divide among different tasks (See, e.g., Baumeister and Tierney, 2011).

Equations (1) and (2) formalize the difficulty in establishing a causal relationship between outcomes and traits. Multiple traits, effort, and acquired skills generate performance in a given task. Many studies in psychology and economics do not control for these inputs and equate measurement of a set of outcomes with the trait the analyst is trying to measure. ${ }^{47}$ This practice can lead to a substantial bias in inference about any particular trait.

An additional point is that most studies assume a linear relationship between outcomes and traits. This practice is particularly problematic for measuring personality traits, where the effect of a trait on an outcome is not always linear or even monotonic. Too much of a

\footnotetext{
${ }^{46}$ The empirical relationship between measured preference parameters and Big Five measures is weak.

${ }^{47}$ Selecting measures and verifying them is part of the sometimes mysterious and inherently subjective process of "construct validity" in psychology. For a discussion, see Borghans et al. (2008).
} 
good thing can be bad $\left(\frac{\partial \phi_{a}}{\partial P_{a}}<0\right.$ for $P_{a}>\bar{P}$ for threshold $\left.\bar{P}\right)$. For example, extreme levels of traits are associated with psychopathologies. High levels of Conscientiousness are associated with Obsessive Compulsive Disorder, which hinders task performance (Samuel and Widiger, 2008). Nonlinearities can also arise when traits and incentives interact, as in the analyses of Borghans et al. (2008) and Segal (2008) who show that people with different personality traits respond differently to incentives on tests. 48

The traits and other acquired skills evolve over time through investment and habituation. Equation (3) shows that traits at age $a+1$ are age-dependent functions of cognitive ability, personality traits, other acquired skills, and investment $I_{a}$ at age $a$. In this way, previous levels of traits and acquired skill affect current levels of traits and acquired skill. Equation (3) formalizes the notion that the traits and skills governing performance at a point in time are themselves the outcome of investment and habituation:

$$
\left(C_{a+1}, P_{a+1}, K_{a+1}\right)=\eta_{a}(C_{a}, P_{a}, K_{a}, \underbrace{I_{a}}_{\begin{array}{c}
\text { Investment } \\
\text { and } \\
\text { experience }
\end{array}}), \quad a=1, \ldots, A
$$

In conjunction with resource constraints, a "deeper" set of preference parameters at age $a$ may govern investment decisions and effort allocated to tasks.

\subsection{Extreme Examples of Personality Change}

Laboratory experiments and brain lesion studies provide some of the most compelling evidence that personality traits can change and that the change affects behaviors. The most famous example is that of Phineas Gage, a railway construction foreman whose head was impaled by a metal spike. Miraculously he retained his problem solving abilities, but he changed from being polite and dependable to being rude and unreliable. His personality change caused him to lose his job and alienate family members (Damasio et al., 2005). Lab-

\footnotetext{
${ }^{48}$ Formally, this occurs when $\frac{\partial^{2} \psi_{T_{a}}}{\partial P_{a} \partial R_{T_{a}}} \neq 0$.
} 
oratory experiments show that expressed traits can be manipulated temporarily. Magnetic disruption of the left lateral prefrontal cortex can increase experimentally elicited discount rates (Figner et al., 2010) and nasal sprays of oxytocin increase trust (Kosfeld et al., 2005).

\subsection{Evidence from the GED Testing Program}

The GED is a standardized achievement test that serves as an alternative to a high school diploma. High school dropouts can take the seven-hour GED exam to certify that they have the "general knowledge" of a high school graduate. The test is widely used. The GED testing program currently produces $12 \%$ of high school certificates each year in the United States. We draw on the analysis of Heckman et al. (2012) and first present results for males. The GED program provides insight into the effects of personality traits on outcomes. GED recipients have the same cognitive ability as high school graduates, but differ in their personality traits.

Table 4 shows the correlations between GED scores and other achievement test scores. GED test scores are strongly correlated with scores on other standardized achievement tests. The correlations range from 0.61 with the General Aptitude Test Battery (GATB) to 0.88 with the Iowa Test of Educational Development, the progenitor of the GED. 
Table 4: Validities of GED Test

\begin{tabular}{lll}
\hline Test & Correlation & Source(s) \\
\hline Armed Forces Qualification Test (AFQT) & $0.75-0.79^{\dagger}$ & Means and Laurence $(1984)$ \\
Iowa Test of Educational Development & $0.88^{\dagger}$ & Means and Laurence $(1984)$ \\
American College Test (ACT) & $0.80^{\dagger}$ & Means and Laurence $(1984)$ \\
Adult Performance Level (APL) Survey & $0.81^{\dagger}$ & Means and Laurence $(1984)$ \\
New York's Degrees of Reading Power (DRP) Test & $0.77^{\dagger}$ & Means and Laurence $(1984)$ \\
Test of Adult Basic Education (TABE) & $0.66-0.68^{\dagger}$ & Means and Laurence $(1984)$ \\
General Aptitude Test Battery (GATB) & $0.61-0.67^{\dagger}$ & Means and Laurence $(1984)$ \\
National Adult Literacy Survey (NALS) factor & $0.78^{\ddagger}$ & Baldwin (1995) \\
\end{tabular}

$\dagger$ Uses mean GED subtest scores

$\ddagger$ Uses a general GED factor

GED recipients are smarter than other dropouts. Figure 5 shows the distributions of a factor extracted from the components of the Armed Services Vocational Aptitude Battery (ASVAB) for male high school dropouts, GED recipients, and high school graduates 49 The sample excludes people who attend post-secondary education. The distribution of the scores of GED recipients is much more like that of high school graduates than that of high school dropouts.

\footnotetext{
${ }^{49}$ Similar results are found for females.
} 
Figure 5: Cognitive ability by educational status

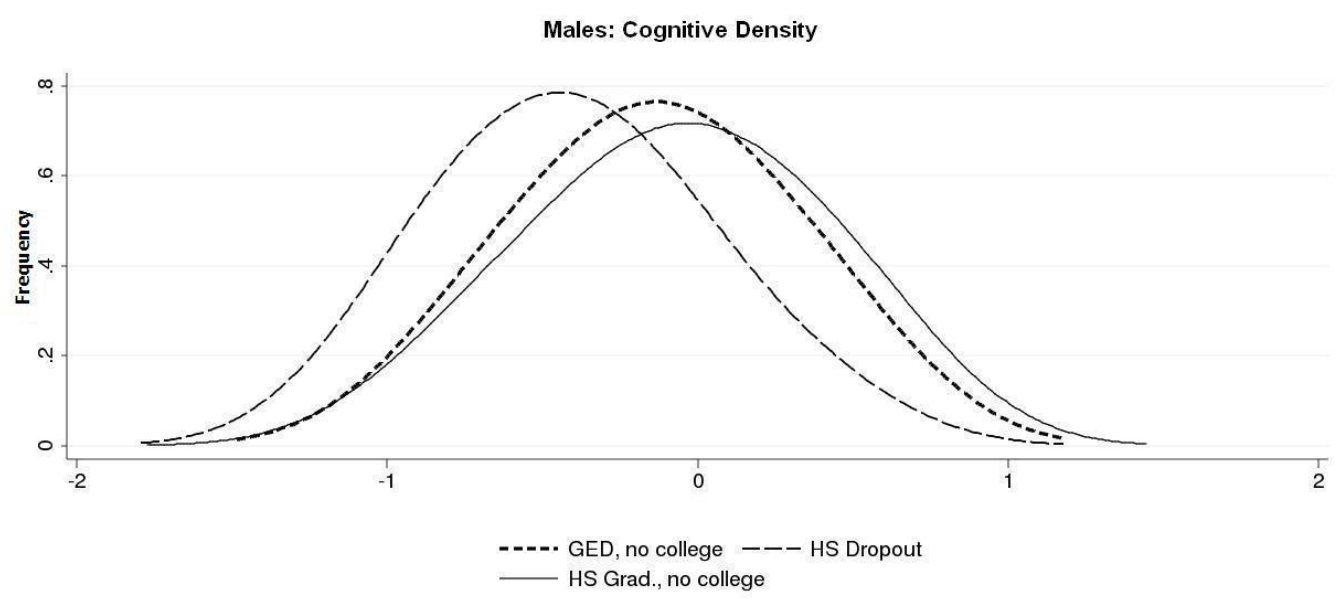

Source: Reproduced from Heckman et al. (2011), which uses data from the National Longitudinal Study of Youth 1979 (NLSY79). Notes: The distributions above represent cognitive ability factors estimated using a subset of the Armed Services Vocational Aptitude Battery (ASVAB) and educational attainment as laid out in Hansen et al. (2004). The sample is restricted to the cross-sectional subsample for both males and females. Distributions show only those with no post-secondary educational attainment. The cognitive ability factors are normalized by gender to be mean zero standard deviation one.

If they have the same cognitive ability as high school graduates, then why do they drop out of high school? Success in school requires other traits. On a variety of other dimensions, GED recipients behave much more like other dropouts. Figure 6 shows measures of early adolescent drug use, crime, sex, and violence extracted from three data sources 50 Male high school graduates perform better on all measures than high school dropouts or GED recipients. GED recipients are much more similar to dropouts, but in several cases are statistically significantly more likely to engage in risky behaviors than other dropouts. On no outcome measure in that figure are dropouts statistically significantly more likely to engage in risky behaviors compared to GED recipients. Figure 7 summarizes these adolescent behaviors using a single factor and shows that unlike the cognitive summary measures, the distribution of the noncognitive (personality) summary measure of GED recipients is much closer to that of dropouts than to that of high school graduates.

\footnotetext{
${ }^{50}$ See National Longitudinal Survey of Youth 1979 (NLSY79), National Longitudinal Survey of Youth 1997 (NLSY97), and National Educational Longitudinal Survey (NELS). For discussion of these data sets, see Heckman et al. (2012).
} 
Figure 6: Measures of Adolescent Behaviors for Male Dropouts, GED Recipients, and High School Graduates

(a) Smoking and Drinking

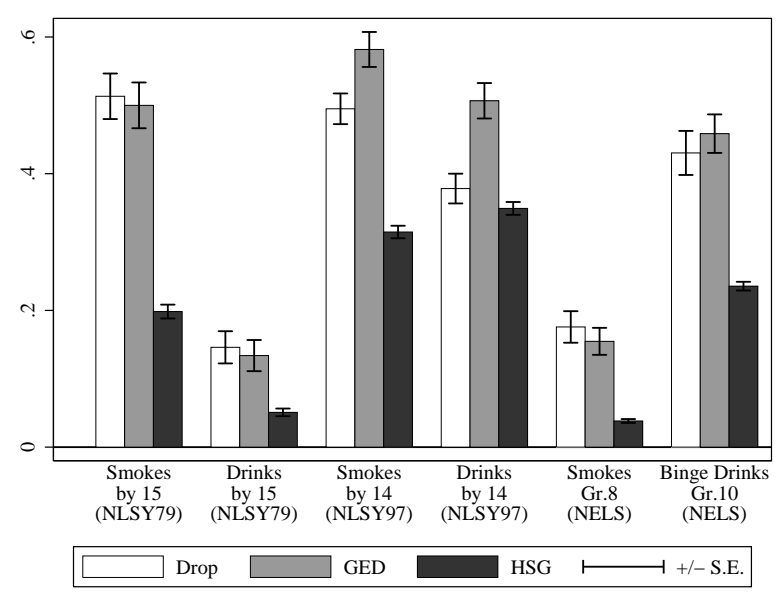

(b) Sex and Violent Behavior

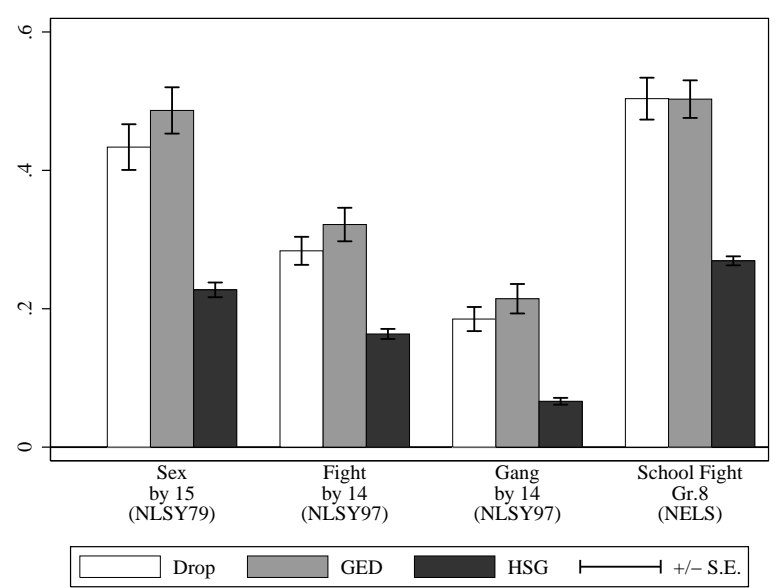

(c) Criminal Behavior

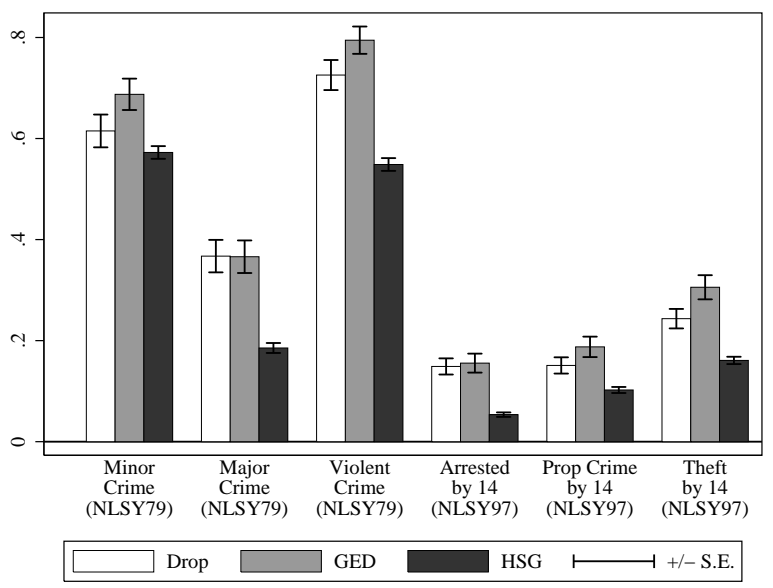

Sources: Heckman et al. (2012 Chapter 3). National Longitudinal Survey of Youth 1979, National Longitudinal Survey of Youth 1997, National Educational Longitudinal Survey. Notes: Minor crime includes vandalism, shoplifting, petty theft, fraud, holding or selling stolen goods. Major crime includes auto theft, breaking/entering private property, grand theft. Violent crime includes fighting, assault, aggravated assault. Tests of Significance: The estimates for GED recipients and high school graduates are statistically significantly different at the $5 \%$ level for all variables. The estimates for dropouts and high school graduates are statistically significantly different at the $5 \%$ level for all variables, except for "Minor Crime (NLSY79)" and "Drinks by 14 (NLSY97)." The estimates of "Smokes by 14 (NLSY97)," "Drinks by 14 (NLSY97)," and "Theft by 14 (NLSY97)" between GED recipients and dropouts are statistically significantly different at the $5 \%$ level. 
Figure 7: Distribution of a Summary Measure of Noncognitive Ability by Education Group

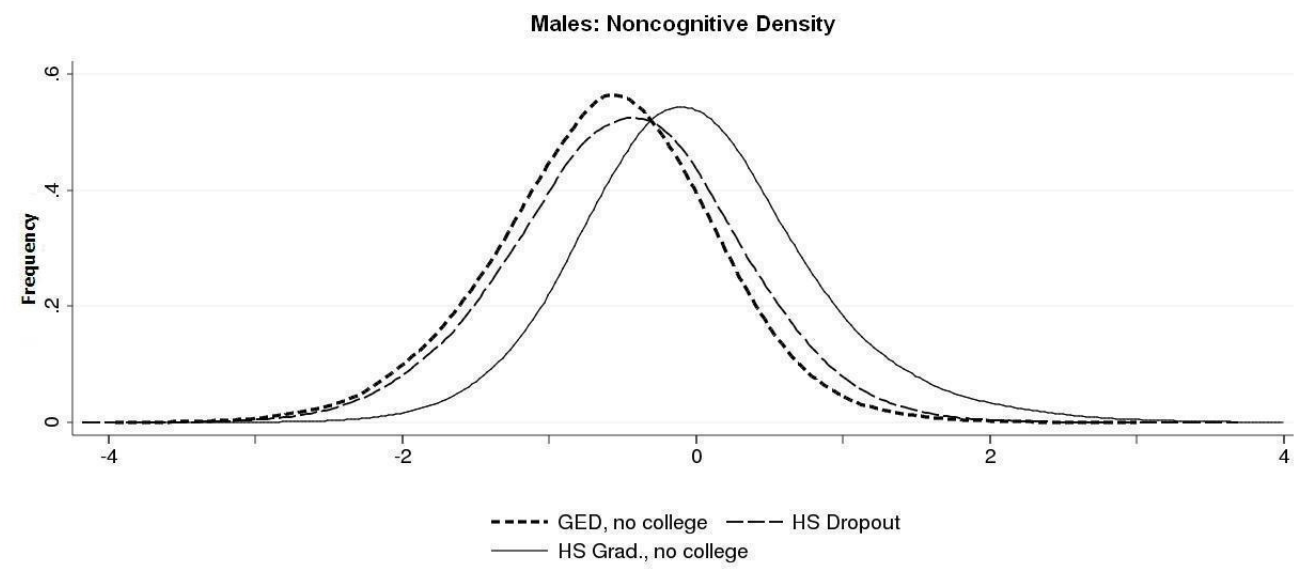

Source: Reproduced from Heckman et al. (2011), which uses data from the National Longitudinal Study of Youth 1979 (NLSY79). Notes: The distributions above represent non-cognitive ability factors estimated using measures of early violent crime, minor crime, marijuana use, regular smoking, drinking, early sexual intercourse, and educational attainment as in Hansen et al. (2004). Sample restricted to the cross-sectional subsample for both males and females. Distributions show only those with no post-secondary educational attainment. The non-cognitive ability factors normalized to be mean zero standard deviation one.

The traits that cause GED recipients to drop out of high school manifest themselves in many other life outcomes. One potential benefit of the GED certificate is that it opens doors to post-secondary education. Figure 8 shows post-secondary educational attainment for GED recipients and high school graduates. About 40\% of GED recipients enroll in a 2or 4- year college. Nearly half drop out within the first year. Only 3-4\% earn a BA or AA degree by age 40 . 
Figure 8: Post-Secondary Educational Attainment Across Education Groups Through Age 40 (NLSY79) - Males

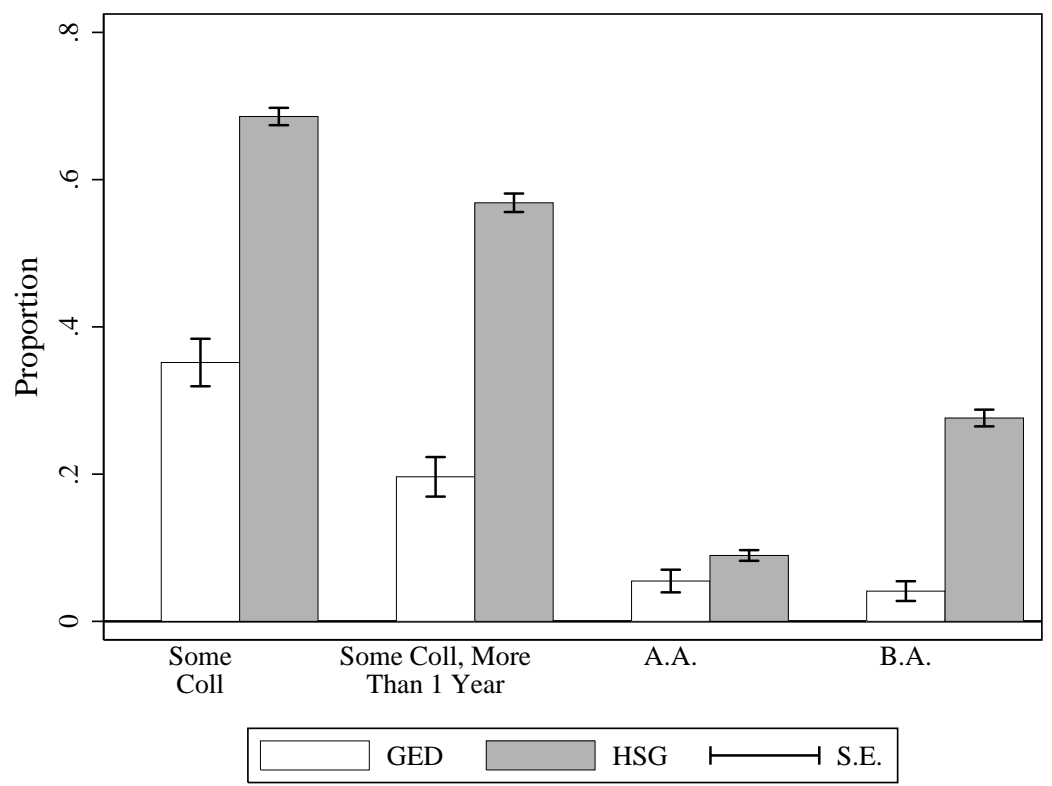

Sources: Heckman et al. (2012, Chapter 4). National Longitudinal Survey of Youth 1979. Notes: The graph shows postsecondary educational attainment of GED recipients and high school graduates. Variable Definitions: "Some College" represents people who entered any post-secondary institution ever. "Some College, More Than a Year" represents people who completed at least a year of some post-secondary education ever. "A.A." represents people who obtained associate's degrees ever. "B.A." represents people who obtained bachelor's degrees ever. "B.A." also includes people with higher education: M.A. Ph.D and professional degrees. Tests of Significance: The estimates for GED recipients and high school graduates are statistically significantly different at the $5 \%$ level for all but attainment of the A.A. degree.

GED recipients lack persistence in a variety of tasks in life. Figure 9 shows the survival rates in employment (overall), employment in a given job, marriage, and in the condition of not having been incarcerated. GED recipients tend to exit employment, become divorced, and enter jail at rates similar to those of high school dropouts, while high school graduates are much more persistent. 
Figure 9: Survival Rates in Various States for Male Dropouts, GED Recipients, and High School Graduates

(a) Survival Rate in Employment

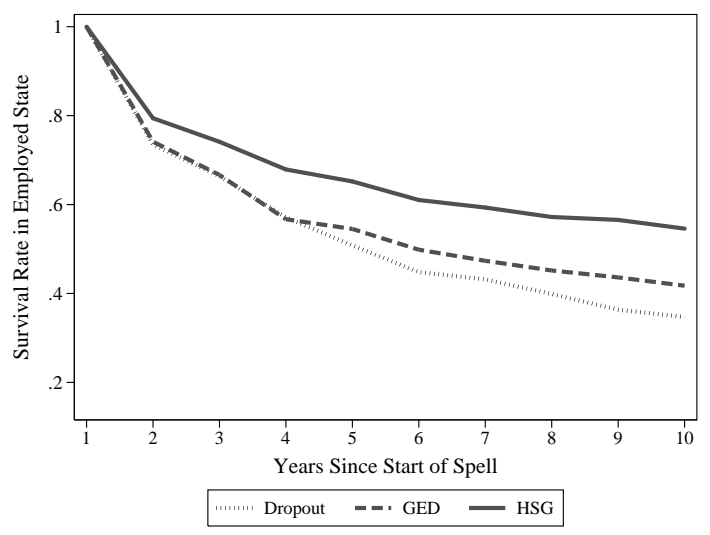

(c) Survival Rate in Marriage

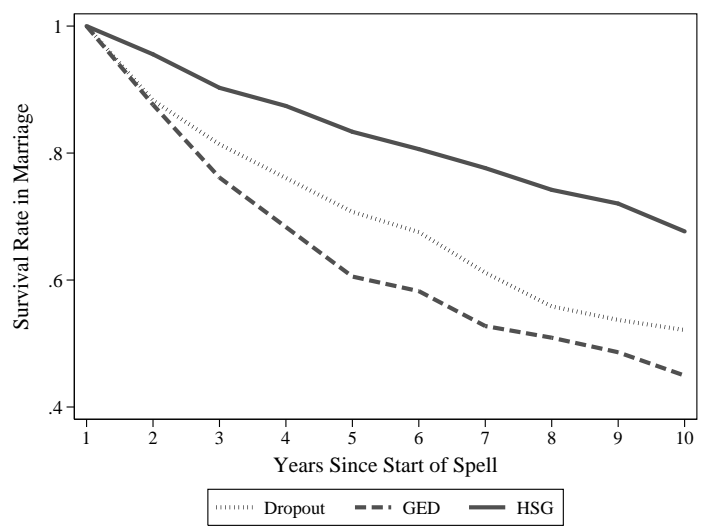

(b) Survival Rate in Staying on a Job

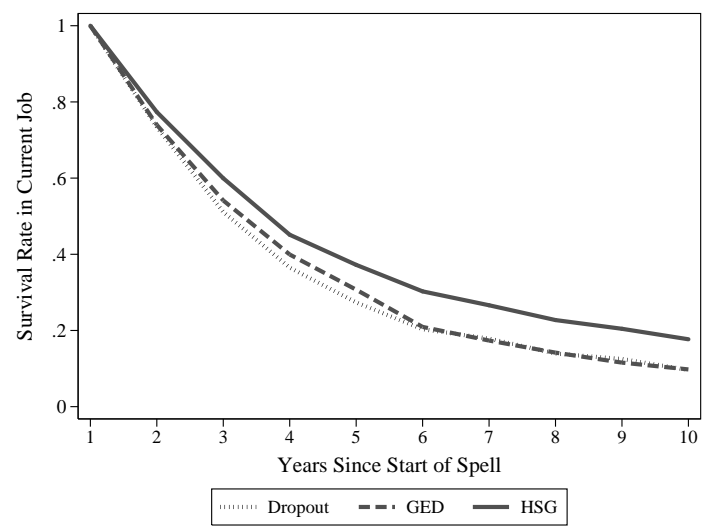

(d) Survival Rate in Staying Out of Jail

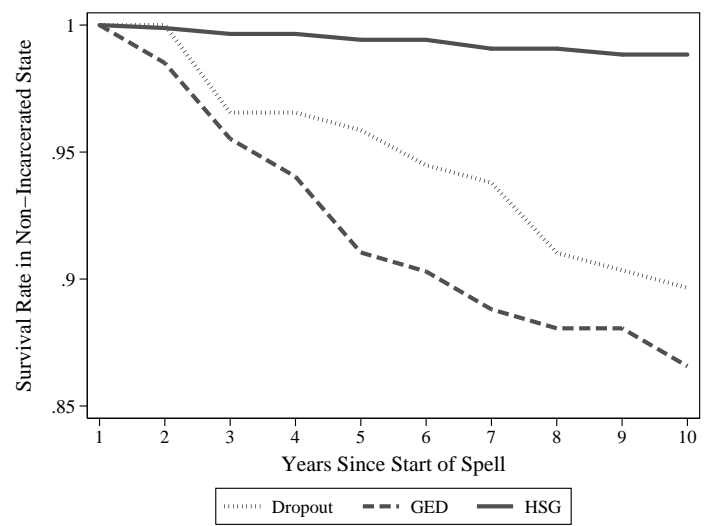

Source: Heckman et al. (2012, Chapter 4). National Longitudinal Survey of Youth 1979 (NLSY79), nationally representative cross sectional sample. Notes: The spell to first time being incarcerated begins in the first year that individuals exit school. Tests of Significance: The estimates for GED recipients and high school graduates are statistically significantly different at the $5 \%$ level for all but the 2nd year of "Survival Rate in Not Having Been Incarcerated." The estimates for dropouts and high school graduates are statistically significantly different at the $5 \%$ level for all but the 2nd year of "Survival Rate in Not Having Been Incarcerated." The estimates for dropouts and GED are statistically only significantly different at the $5 \%$ level for the 5th year of the "Survival Rate in Marriage."

Adjusting for their differences in cognitive ability, male GED recipients perform virtually the same as high school dropouts in the labor market. Figure 10 shows the hourly wages and annual earnings of male GED recipients and high school graduates compared to high school dropouts for different age groups. The first set of bars shows the outcomes after adjusting for age, race, and region of residence. The second set of bars shows the effects 
after additionally adjusting for scores on the Armed Forces Qualifying Test (AFQT). The third set of bars shows the effects after additionally adjusting for standard measures of family background. GED recipients and high school graduates outperform dropouts in regressions that only adjust for age, race, and region of residence. After adjusting for cognitive ability, GED recipients are indistinguishable from dropouts, whereas high school graduates earn more and have higher hourly wages. Controlling for family background characteristics does not change the story. 
Figure 10: Labor Market Outcomes Differences - By Age - NLSY79 - Males

(a) Annual Earnings

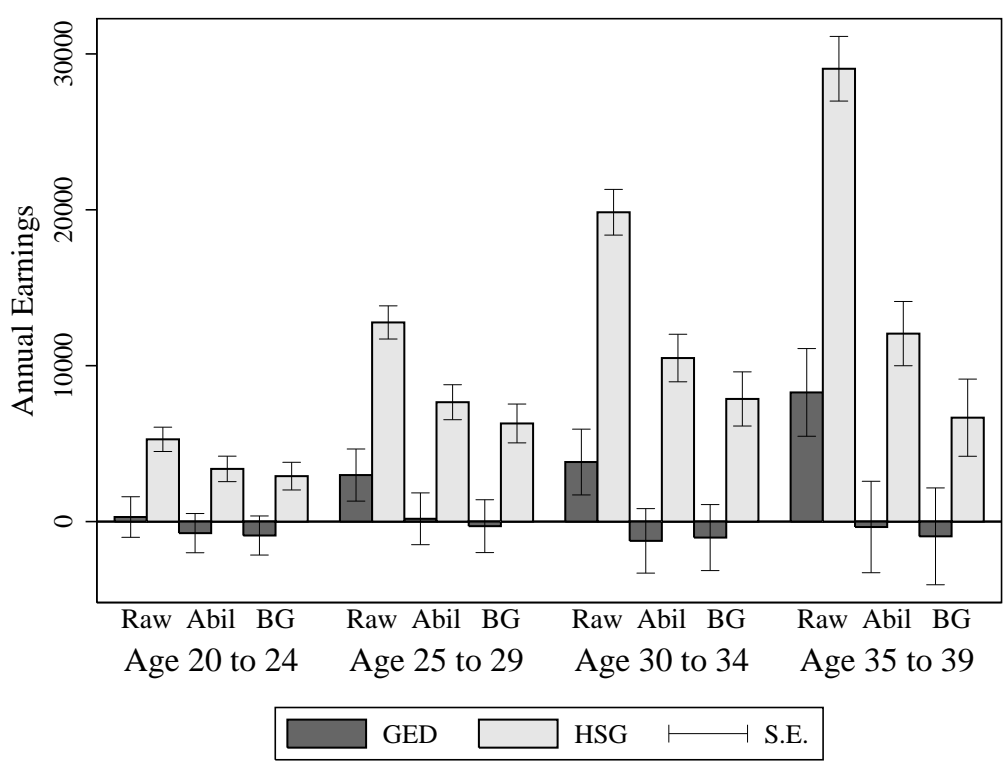

(b) Hourly Wage

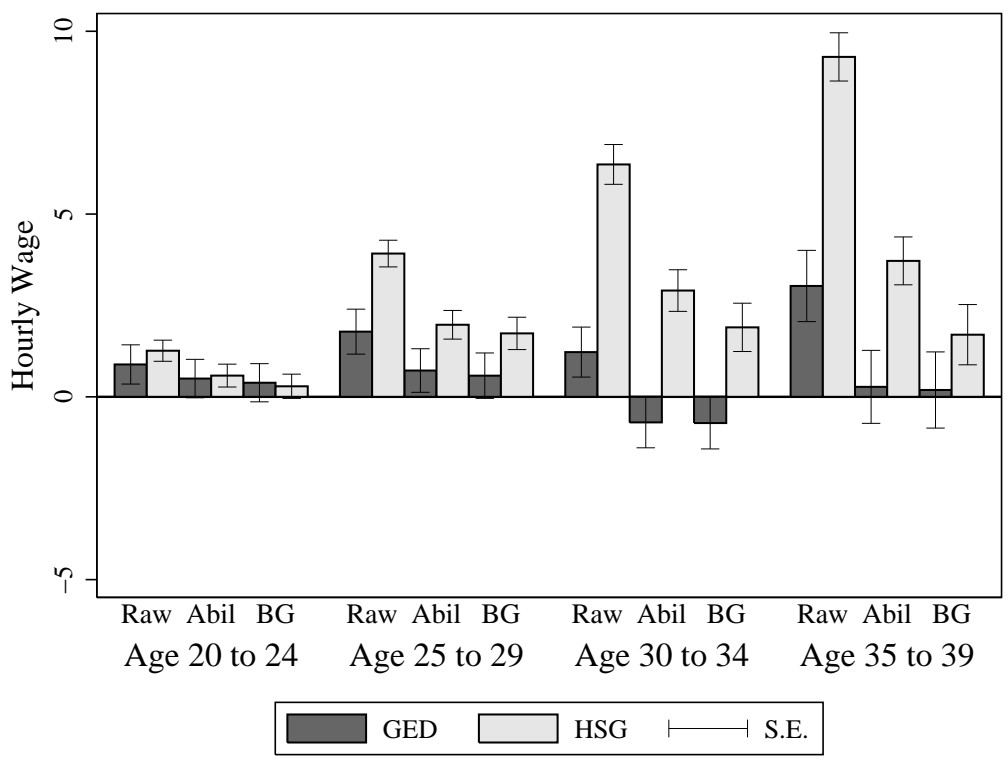

Source: Heckman et al. (2012, Chapter 3). National Longitudinal Survey of Youth 1979. Controls: “Raw" - age, race, and region of residence; "Abil" -age, race, region of residence, and AFQT adjusted for schooling at time of test; "BG" mother's highest grade completed, urban status at age 14, family income in 1978, broken home status at age 14, south at age 14, AFQT, and factors based on adolescent behavioral measures, crime and school performance. Regressions exclude those reporting earning more than $\$ 300,000$ or working more than 4,000 hours. Notes: All regressions allow for heteroskedastic errors and when appropriate clustering at the individual level. 
Most of the patterns found for women parallel those found for men. However, there are some important differences. ${ }^{51}$ While female GED recipients share similar cognitive and personality traits as male GED recipients, their outcomes differ. After accounting for differences in cognitive ability, female GED recipients do not earn higher hourly wages than other dropouts, but unlike men they have higher annual earnings because they are more likely to participate in the labor force. 52

\subsection{Evidence from The Perry Preschool Program and Other In- terventions}

Evidence from the Perry Preschool Program shows how personality traits can be changed in ways that produce beneficial lifetime outcomes. The Perry preschool Program enriched the lives of three- and four-year-old low-income, Black children with initial IQs below 85 at age 35

Participants were taught social skills in a "plan-do-review" sequence where students planned a task, executed it, and then reviewed it with teachers and fellow students. They learned to work with others when problems arose 54 In addition, home visits promoted parent-child interactions. The program ended after two years of enrollment and both treatments and controls entered the same school. The program was evaluated by the method of random assignment.

The program did not improve IQ scores in a lasting way. Figure 11 shows that, by age ten, treatment and control groups had the same average IQ scores. Many critics of early childhood programs seize on this finding and related evidence to dismiss the value of early

\footnotetext{
${ }^{51}$ See Heckman et al. (2012).

${ }^{52}$ The increased labor supply response is largely due to female GED recipients who attain some postsecondary education or who have dropped out of high school due to pregnancy. See Heckman et al. (2012) for a full discussion of the evidence on the performance of GED recipients.

${ }^{53}$ We draw on the analysis of Heckman et al. (2012).

${ }^{54}$ Sylva (1997) describes the Perry program as a Vygotskian program fostering personality traits. Vygotsky developed a psychology of child development in structured social settings that emphasized development of social and personality skills.
} 
intervention studies.

Figure 11: Perry Preschool Program: IQ, by Age and Treatment Group

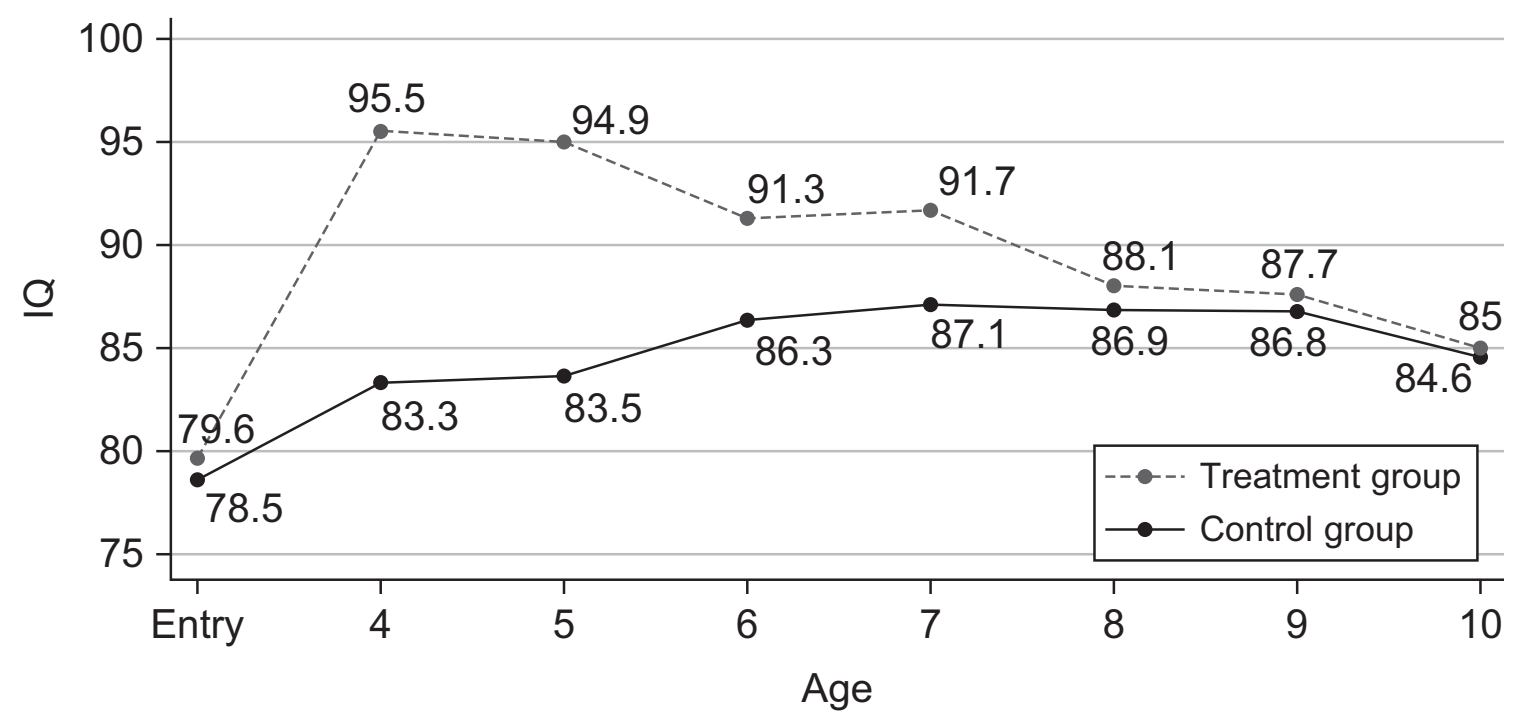

Notes: IQ measured on the Stanford-Binet Intelligence Scale (Terman and Merrill, 1960). The test was administered at program entry and at each of the ages indicated. Source: Cunha et al. (2006) and Heckman and Masterov (2007) based on data provided by the High Scope Foundation.

Nevertheless, the program improved outcomes for both boys and girls, resulting in a statistically significant rate of return of around 6-10\% per annum for both boys and girls. (See Heckman et al., 2010.) These returns are above the post-World War II, pre-2008 meltdown in stock market returns to equity estimated to be $5.8 \%$ per annum 55

The Perry Preschool Program worked primarily through improving personality traits. Participants had better direct measures of personal behavior (a weighted average of "absences and truancies," "lying and cheating," "stealing," and "swears or uses obscene words" measured by teachers in the elementary school years). Participants of both genders improved their "externalizing behavior," a psychological construct related to Agreeableness and Conscientiousness. For girls, the program improved Openness to Experience (proxied by academic motivation). The program also improved scores on the California Achievement

\footnotetext{
${ }^{55}$ See DeLong and Magin (2009).
} 
Test (CAT). This evidence is consistent with the evidence presented in the previous section that shows that performance on achievement tests depends on personality traits.

Other studies are broadly consistent with the evidence from the Perry Preschool study. Analyses of data from Project STAR, a program that randomly assigned kindergartners and teachers to classes of different sizes, yields results similar to the Perry Program. Using data from Project STAR, Dee and West (2011) find that assignment to a small class is associated with positive changes in personality. In a follow-up analysis, Chetty et al. (2011) examine the Project STAR program and find that students placed in higher quality kindergarten classes-as measured by their peer's average performance on a Stanford Achievement Testhad significantly higher earnings in early adulthood.

The curriculum of Promoting Alternative Thinking Strategies (PATHS) teaches selfcontrol, emotional awareness, and social problem-solving skills and is aimed at elementary school children (see Bierman et al., 2010). A recent random-assignment, longitudinal study demonstrates that the PATHS curriculum reduces teacher and peer ratings of aggression, improves teacher and peer ratings of prosocial behavior, and improves teacher ratings of academic engagement 56 PATHS is an exemplar of school-based social and emotional learning (SEL) programs. A recent meta-analysis shows that the program improved grades by 0.33 standard deviations and achievement test scores by 0.27 standard deviations. Durlak et al., 2011). ${ }^{57}$ Likewise, several random assignment evaluations of Tools of the Mind, a preschool and early primary school curriculum targeting development of self-control, show that it improves classroom behavior as well as executive function, defined as higher-level cognitive skills including inhibitory control, working memory, and cognitive flexibility (Barnett et al. 2008, 2006; Bodrova and Leong, 2001, 2007; Diamond et al., 2007; Lillard and Else-Quest, 2006) ${ }^{58}$ Positive findings are reported for the Montessori preschool curriculum (Lillard and ${ }^{56}$ Bierman et al. $(2010)$.

${ }^{5 /}$ Note however that the largest federal study to date on character education programs, including PATHS, failed to find evidence for improvements in behavior or academic performance (see Social and Character Development Research Consortium, 2010).

${ }^{58}$ However, a more recent large-scale study (Farran and Wilson, 2011) does not find any effect of the program on self-regulation or literacy, language, and mathematics achievement. 
Else-Quest, 2006). Unlike the Perry study, these studies do not have long-term followups.

There is evidence that targeted intervention efforts can improve aspects of Conscientiousness. In contrast to the multi-faceted curricula described above, studies targeting improvement in this trait are designed to isolate a particular mechanism producing behavioral change. For instance, Rueda et al. (2005) designed a set of computer exercises to train attention in children between four and six years of age. Children in the intervention group improved in performance on computer tasks of attention relative to children who instead watched interactive videos for a comparable amount of time. Similarly, Stevens et al. (2008) designed a 6-week computerized intervention and showed that it can improve selective auditory attention (i.e., the ability to attend to a target auditory signal in the face of an irrelevant, distracting auditory signal). As is typical of much of the literature, all of these programs have only short-term follow-ups.

Several studies suggest that personality can be remediated in adolescence. Martins (2010) analyzes data from EPSIS, a program developed to improve student achievement of 13-15 year-olds in Portugal by increasing motivation, self-esteem, and study skills. The program consists of one-on-one meetings with a trained staff member or meetings in small groups. The intervention was tailored to each participant's individual skill deficit. Overall, the program was successful and cost-effective, decreasing grade retention by 10 percentage points.

Other life experiences, like employment, can improve personality. Gottschalk (2005) analyzes evidence from a randomized control trial that working at a job can improve Locus of Control, a trait related to Neuroticism that measures the extent to which individuals believe that they have control over their lives through self-motivation or self-determination as opposed to the extent that the environment controls their lives (Rotter, 1966) 5 He uses data from the Self-Sufficiency Project (SSP) in which some welfare recipients were randomly offered substantial subsidies to work. The subsidy more than doubled the earnings of a minimum wage worker. People in the experimental group worked about $30 \%$ more hours

\footnotetext{
${ }^{59}$ The relationship between Locus of Control and the Big Five trait of Neuroticism is discussed in Almlund et al. (2011).
} 
than those in the control group. After 36 months, those who received the subsidy were more likely to have an improved Locus of Control.

\subsection{Additional Evidence}

Studies that account for the endogeneity of investment and education provide further evidence of the causal effect of education and cognitive and personality traits on outcomes. Heckman et al. (2011) estimate a sequential model of education to study the effects of education on a variety of outcomes. Correcting for selection into education, they find that early cognitive and personality traits affect schooling choices, labor market outcomes, adult health, and social outcomes and that increasing education promotes beneficial labor market, health, and social outcomes.

Heckman et al. (2006) estimate a version of Equation (3) to analyze the effects of increases in education on measured cognition and personality measures ${ }^{60}$ Controlling for the problem of reverse causality that schooling may be caused by traits, they find that schooling improves both personality and cognitive traits and that these traits, in turn, boost outcomes. ${ }^{61}$

Cunha et al. (2010) estimate a model of the technology of skill formation using longitudinal data on the development of children with rich measures of parental investment and child traits. They control for the endogeneity of investment using shocks to family income along with other instruments. Their model is a version of Equation (3). Traits are self-productive and exhibit dynamic complementarity - current values of traits affect the evolution of future traits through direct and cross effects. A leading example of a cross effect is that more motivated children are more likely to learn. They estimate parameters that summarize how past personality traits affect future cognitive traits.

They find that self-productivity becomes stronger as children become older, for both

\footnotetext{
${ }^{60}$ They estimate the effect of schooling on Self-Esteem and Locus of Control, personality traits related to Neuroticism. The Rosenberg Self-Esteem Scale attempts to assess the degree of approval or disapproval of oneself (Rosenberg, 1965). The relationship between these measures and the Big Five traits of Neuroticism is discussed in Almlund et al. (2011).

${ }^{61}$ Both Heckman et al. (2011) and Heckman et al. (2006) use an identification strategy based on matching on proxies for unobserved traits that corrects for measurement error and the endogeneity of schooling.
} 
cognitive and personality traits. The elasticity of substitution for cognitive inputs is smaller later in life. This means that it is more difficult to compensate for the effects of adverse environments on cognitive endowments at later ages than it is at earlier ages. This finding is consistent with the high rank stability of cognition over ages past 10-12 reported in the literature. It also helps to explain the evidence on the ineffectiveness of cognitive remediation strategies for disadvantaged adolescents documented in Cunha et al. (2006); Knudsen et al. (2006) and Cunha and Heckman (2007).

Personality traits foster the development of cognition but not vice versa. It is equally easy at all stages of the child's life cycle to compensate for early disadvantage in endowments using personality traits. (Elasticities of substitution are essentially the same at different stages of the life cycle.) The most effective adolescent interventions target personality traits $\sqrt{62}$

\section{Summary}

This paper reviews recent evidence on the importance of personality in economic and social life. It shows that success in life depends on many traits, not just those measured by IQ, grades, and standardized achievements tests. Personality traits predict and cause outcomes.

All psychological traits are measured by performance on tasks. Psychological traits have different productivities in different tasks. Performance on tasks depends on incentives and multiple traits, giving rise to a fundamental identification problem when measuring any single trait. This identification problem is empirically important even for measures of cognitive traits.

The importance of cognitive ability increases with the complexity of the task. Given their endowments of traits and the incentives they face, people sort into tasks in life in pursuit of their comparative advantage.

Traits are stable across situations, but their manifestation depends on incentives to apply

\footnotetext{
${ }^{62}$ Cunha et al. (2006) report that $16 \%$ of the variation in educational attainment is explained by adolescent cognitive traits, $12 \%$ is due to adolescent personality (socioemotional traits), and $15 \%$ is due to measured parental investments.
} 
effort in the situations where they are measured and also depends on other traits and skills. However, traits are not set in stone. They change over the life cycle and can be enhanced by education, parenting, and environment to different degrees at different ages.

Scores on achievement tests capture both cognitive and personality traits. Children who are more academically motivated and more open to experience learn more and have higher test scores. More motivated children also try harder on achievement tests.

The evidence in this paper should give pause to analysts and policy makers who rely solely on achievement tests to monitor school performance and school systems. Standardized achievement tests do not adequately capture many skills that matter in life. GED recipients perform about as well as high school graduates on achievement tests but perform much worse in many aspects of life because they lack important personality traits. Categorizing GED recipients as high school graduates misrepresents national statistics on educational attainment ${ }^{63}$ The Perry Preschool Program improved the lives of its participants without increasing their IQ scores, demonstrating why it is problematic to focus curricula exclusively on improving cognitive test scores.

Monitoring school progress and creating programs to enhance skills requires a broader framework of measurement. Interventions that promote beneficial changes in personality have an important place in a portfolio of public policies to foster human development.

\footnotetext{
${ }^{63}$ See Heckman and LaFontaine $(2010)$.
} 


\section{References}

Ackerman, P. L. and E. D. Heggestad (1997). Intelligence, personality, and interests: Evidence for overlapping traits. Psychological Bulletin 121, 219-245.

ACT, Inc. (2007). The ACT Technical Manual. Iowa City, IA: ACT, Inc.

Almlund, M., A. Duckworth, J. J. Heckman, and T. Kautz (2011). Personality psychology and economics. In E. A. Hanushek, S. Machin, and L. Wößmann (Eds.), Handbook of the Economics of Education, Volume 4, pp. 1-181. Amsterdam: Elsevier.

Ayllon, T. and K. Kelly (1972). Effects of reinforcement on standardized test performance. Journal of Applied Behavior Analysis 5(4), 477-484.

Baldwin, J. (1995). Who Took the GED? GED 1994 Statistical Report. Washington, D.C.: American Council on Education, GED Testing Service, Center for Adult Learning.

Barnett, W. S., K. Jung, D. J. Yarosz, J. Thomas, A. Hornbeck, R. Stechuk, and S. Burns (2008). Educational effects of the tools of the mind curriculum: A randomized trial. Early Childhood Research Quarterly 23(3), 299-313.

Barnett, W. S., D. J. Yarosz, J. Thomas, and A. Hornbeck (2006). Educational effectiveness of a Vygotskian approach to preschool education: A randomized trial. Technical report, National Institute for Early Education Research, Rutgers, The State University of New Jersey.

Barrick, M. R. and M. K. Mount (1991). The Big Five personality dimensions and job performance: A meta-analysis. Personnel Psychology 44(1), 1-26.

Baumeister, R. F. and J. J. M. Tierney (2011). Willpower : rediscovering the greatest human strength. New York: Penguin Press. 
Benjamin, D. J., S. A. Brown, and J. M. Shapiro (2006, May). Who is 'behavioral'? cognitive ability and anomalous preferences. Unpublished manuscript, Cornell University, Ithaca, NY.

Bierman, K. L., J. D. Coie, K. A. Dodge, M. T. Greenberg, J. E. Lochman, R. J. McMahon, and E. Pinderhughes (2010). The effects of a multiyear universal social-emotional learning program: The role of student and school characteristics. Journal of Consulting and Clinical Psychology 78(2), 156-168.

Binet, A. and T. Simon (1916). The development of intelligence in children (The Binet-Simon Scale). Psychological Science. Baltimore, MD: Williams \& Wilkins Co.

Bodrova, E. and D. J. Leong (2001). Tools of the Mind: A case study of implementing the Vygotskian approach in American early childhood and primary classrooms. Geneva: International Bureau of Education, UNESCO.

Bodrova, E. and D. J. Leong (2007). Tools of the Mind: The Vygotskian Approach to Early Childhood Education. Upper Saddle River: Pearson Education, Inc.

Borghans, L., A. L. Duckworth, J. J. Heckman, and B. ter Weel (2008, Fall). The economics and psychology of personality traits. Journal of Human Resources 43(4), 972-1059.

Borghans, L., B. H. H. Golsteyn, J. J. Heckman, and J. E. Humphries (2011a). Identification problems in personality psychology. Personality and Individual Differences 51 (Special Issue on Personality and Economics), 315-320. E. Ferguson, J.J. Heckman, and P. Corr, editors.

Borghans, L., B. H. H. Golsteyn, J. J. Heckman, and J. E. Humphries (2011b). Reinterpreting estimated effects of cognition on social outcomes. Unpublished manuscript, Department of Economics, University of Chicago. 
Borghans, L., H. Meijers, and B. ter Weel (2008, January). The role of noncognitive skills in explaining cognitive test scores. Economic Inquiry 46(1), 2-12.

Bouchard, T. J. and J. C. Loehlin (2001, May). Genes, evolution and personality. Behavior Genetics 31(3), 243-273.

Bound, J., C. Brown, and N. Mathiowetz (2001). Measurement error in survey data. In J. J. Heckman and E. Leamer (Eds.), Handbook of Econometrics, Volume 5 of Handbooks in Economics, pp. 3705-3843. Amsterdam: Elsevier Science.

Bowen, W. G., M. M. Chingos, and M. S. McPherson (2009). Test scores and high school grades as predictors. In Crossing the finish line: Completing college at America's public universities, pp. 112-133. Princeton, NJ: Princeton University Press.

Bowles, S. and H. Gintis (1976). Schooling in Capitalist America: Educational Reform and the Contradictions of Economic Life. New York: Basic Books.

Bowles, S., H. Gintis, and M. Osborne (2001, December). The determinants of earnings: A behavioral approach. Journal of Economic Literature 39(4), 1137-1176.

Breuning, S. E. and W. F. Zella (1978). Effects of individualized incentives on normreferenced IQ test performance of high school students in special education classes. Journal of School Psychology 16(3), 220.

Canli, T. (2006). Biology of Personality and Individual Differences. New York: Guilford Press.

Carroll, C. D. (1994, February). How does future income affect current consumption? Quarterly Journal of Economics 109(1), 111-147.

Carroll, J. B. (1993). Human Cognitive Abilities: A Survey of Factor-Analytic Studies. New York: Cambridge University Press. 
Cattan, S. (2012). Heterogeneity and selection in the labor market. PhD Thesis, Economics Department, University of Chicago.

Chetty, R., J. N. Friedman, N. Hilger, E. Saez, S. W. Diane, and D. Yagan (2011). How does your kindergarten classroom affect your earnings? evidence from Project STAR. Quarterly Journal of Economics 126(4), 1593-1660.

Clingman, J. and R. L. Fowler (1976). The effects of primary reward on the I.Q. performance of grade-school children as a function of initial I.Q. level. Journal of Applied Behavior Analysis 9(1), 19-23.

Cloninger, C. R., D. M. Svrakic, C. Bayon, and T. R. Przybeck (1999). Measurement of psychopathology as variants of personality. In C. R. Cloninger (Ed.), Personality and psychopathology. Arlington, VA: American Psychiatric Publishing, Inc.

Costa, P. T. and R. R. McCrae (1992a). Four ways five factors are basic. Personality and Individual Difference 13(6), 653-665.

Costa, P. T. and R. R. McCrae (1992b). Revised NEO Personality Inventory (NEO PI$R$ ) and the NEO Five-Factor Inventory (NEO-FFI) professional manual. Odessa, FL: Psychological Assessment Resources.

Cunha, F. and J. J. Heckman (2007, May). The technology of skill formation. American Economic Review 97(2), 31-47.

Cunha, F., J. J. Heckman, L. J. Lochner, and D. V. Masterov (2006). Interpreting the evidence on life cycle skill formation. In E. A. Hanushek and F. Welch (Eds.), Handbook of the Economics of Education, Chapter 12, pp. 697-812. Amsterdam: North-Holland.

Cunha, F., J. J. Heckman, and S. M. Schennach (2010, May). Estimating the technology of cognitive and noncognitive skill formation. Econometrica 78(3), 883-931. 
Damasio, H., T. Grabowski, R. Frank, A. M. Galaburda, and A. R. Damasio (2005). The return of Phineas Gage: Clues about the brain from the skull of a famous patient. In J. T. Cacioppo and G. G. Berntson (Eds.), Social neuroscience: Key readings, pp. 21-28. New York, NY: Psychology Press.

Dee, T. S. and M. R. West (2011). The non-cognitive returns to class size. Educational Evaluation and Policy Analysis 33(1), 23-46.

DeLong, J. and K. Magin (2009, Winter). The U.S. equity return premium: Past, present and future. Journal of Economic Perspectives 23(1), 193208.

Devlin, B., M. Daniels, and K. Roeder (1997). The heritability of IQ. Nature 388(6641), $468-471$.

DeYoung, C. G., J. B. Hirsh, M. S. Shane, X. Papademetris, N. Rajeevan, and J. R. Gray (2010). Testing predictions from personality neuroscience: Brain structure and the Big Five. Psychological Science 21(6), 820-828.

Diamond, A., S. Barnett, J. Thomas, and S. Munro (2007). Preschool program improves cognitive control. Science 318(5855), 1387-1388.

Duckworth, A. L., C. Peterson, M. D. Matthews, and D. R. Kelly (2007, June). Grit: Perseverance and passion for long-term goals. Journal of Personality and Social Psychology 92(6), 1087-1101.

Durlak, J. A., R. P. Weissberg, A. B. Dymnicki, R. D. Taylor, and K. B. Schellinger (2011). The impact of enhancing students social and emotional learning: A meta-analysis of schoolbased universal interventions. Child Development 82(1), 405-432.

Edlund, C. V. (1972). The effect on the behavior of children, as reflected in the IQ scores, when reinforced after each correct response. Journal of Applied Behavior Analysis 5(3), $317-319$. 
Epstein, S. (1979). The stability of behavior: I. on predicting most of the people much of the time. Journal of Personality and Social Psychology 37(7), 1097-1126.

Farran, Dale C., L. M. W. and S. Wilson (2011, August). Experimental evaluation of the Tools of the Mind pre-k curriculum. Technical report, Peabody Research Institute Report.

Feingold, A. (1982). The validity of the information and vocabulary subtests of the WAIS. Journal of Clinical Psychology 38(1), 169-174.

Figner, B., D. Knoch, E. J. Johnson, A. R. Krosch, S. H. Lisanby, E. Fehr, and E. U. Weber (2010). Lateral prefrontal cortex and self-control in intertemporal choice. Nature Neuroscience 13(5), 538-539.

Flynn, J. R. (2007). What is Intelligence?: Beyond the Flynn Effect. New York: Cambridge University Press.

Friedman, D. and A. H. Streicher (1985). Reliability of scores for fiscal year 1981 army applicants: Armed services vocational aptitude battery forms 8, 9, and 10. Technical report, Defense Technical Information Center.

GED Testing Service (2009, March). The technical manual: 2002 series GED tests. Technical manual, American Council on Education and GED Testing Service, Washington, DC. http://www . acenet.edu/Content/NavigationMenu/ged/pubs/TechnicalManual_ 2002SeriesGEDTests.pdf.

Gensowski, M. (2012). Personality, iq, and lifetime earnings. Unpublished manuscript, University of Chicago, Department of Economics.

Gottfredson, L. S. (1997, January-February). Why g matters: The complexity of everyday life. Intelligence 24(1), 79-132.

Gottschalk, P. (2005). Can work alter welfare recipients' beliefs? Journal of Policy Analysis and Management 24(3), 485-498. 
Gough, H. G. and A. B. Heilbrun (1983). The Adjective Check List Manual. Palo Alto, CA: Consulting Psychologists Press.

Greene, A. C., G. L. Sapp, and B. Chissom (1990). Validation of the Stanford-Binet Intelligence Scale: Fourth edition with exceptional black male students. Psychology in the Schools 27(1), 35-41.

Grek, S. (2009). Governing by numbers: the pisa effectin europe. Journal of Education Policy 24 (1), 23-37.

Hansen, K. T., J. J. Heckman, and K. J. Mullen (2004, July-August). The effect of schooling and ability on achievement test scores. Journal of Econometrics 121(1-2), 39-98.

Hartlage, L. C. and C. T. Steele (1977). WISC and WISC-R correlates of academic achievement. Psychology in the Schools 14(1), 15-18.

Heckman, J. J., J. E. Humphries, and T. Kautz (2012). The GED and the Problem of Character in American Society. Unpublished book manuscript, University of Chicago, Department of Economics.

Heckman, J. J., J. E. Humphries, and N. Mader (2011). The GED. In E. A. Hanushek, S. Machin, and L. Wößmann (Eds.), Handbook of the Economics of Education, Volume 3, Chapter 9, pp. 423-484. Amsterdam: North Holland, Elsevier.

Heckman, J. J., J. E. Humphries, S. Urzúa, and G. Veramendi (2011). The effects of educational choices on labor market, health, and social outcomes. Unpublished manuscript, University of Chicago, Department of Economics.

Heckman, J. J. and P. A. LaFontaine (2010, May). The American high school graduation rate: Trends and levels. Review of Economics and Statistics 92(2), 244-262.

Heckman, J. J., L. Malofeeva, R. Pinto, and P. A. Savelyev (2012). Understanding the mechanisms through which an influential early childhood program boosted adult outcomes. 
Unpublished manuscript, University of Chicago, Department of Economics (first draft, 2008). Under revision, American Economic Review.

Heckman, J. J. and D. V. Masterov (2007). The productivity argument for investing in young children. Review of Agricultural Economics 29(3), 446-493.

Heckman, J. J., S. H. Moon, R. Pinto, P. A. Savelyev, A. Shaikh, and A. Q. Yavitz (2006). The Perry Preschool Project: A reanalysis. Unpublished manuscript, University of Chicago, Department of Economics.

Heckman, J. J., S. H. Moon, R. Pinto, P. A. Savelyev, and A. Q. Yavitz (2010, February). The rate of return to the HighScope Perry Preschool Program. Journal of Public Economics 94(1-2), 114-128.

Heckman, J. J., J. Stixrud, and S. Urzua (2006, July). The effects of cognitive and noncognitive abilities on labor market outcomes and social behavior. Journal of Labor Economics $24(3), 411-482$.

Herrnstein, R. J. and C. A. Murray (1994). The Bell Curve: Intelligence and Class Structure in American Life. New York: Free Press.

Holt, M. M. and T. R. Hobbs (1979). The effects of token reinforcement, feedback and response cost on standardized test performance. Behaviour Research and Therapy 17(1), $81-83$.

Jencks, C. (1979). Who Gets Ahead? The Determinants of Economic Success in America. New York: Basic Books.

John, O. P. and S. Srivastava (1999). The big five trait taxonomy: History, measurement and theoretical perspectives. In L. A. Pervin and O. P. John (Eds.), Handbook of Personality: Theory and Research, Chapter 4, pp. 102-138. New York: The Guilford Press. 
Kettner, N. (1976). Armed services vocational aptitude battery (ASVAB form 5): Comparison with GATB and DAT tests: Final report for period May 1975-October 1976. Technical report, DTIC Document: Department of Defense, Department of the Air Force, Air Force Systems Command, Air Force Human Resources Laboratory.

Knudsen, E. I., J. J. Heckman, J. Cameron, and J. P. Shonkoff (2006, July). Economic, neurobiological, and behavioral perspectives on building America's future workforce. Proceedings of the National Academy of Sciences 103(27), 10155-10162.

Kobrin, J. L., B. F. Patterson, E. J. Shaw, K. D. Mattern, and S. M. Barbuti (2008). Validity of the SAT for predicting first-year college grade point average. The College Board 5, 1-10.

Kosfeld, M., M. Heinrichs, P. J. Zak, U. Fischbacher, and E. Fehr (2005). Oxytocin increases trust in humans. Nature 435(7042), 673-676.

Larson, G. E., D. P. Saccuzzo, and J. Brown (1994). Motivation: Cause or confound in information processing/intelligence correlations? Acta Psychologica 85(1), 25-37.

Lemann, N. (1999). The Big Test: The Secret History of the American Meritocracy. New York: Farrar, Straus and Giroux.

Lillard, A. and N. Else-Quest (2006). The early years: Evaluating Montessori. Science 313(5795), 1893-1894.

Lindquist, E. F. (1951). Preliminary considerations in objective test construction. In E. F. Lindquist (Ed.), Educational Measurement, pp. 119-184. Washington, DC: American Council on Education.

Martins, P. S. (2010). Can targeted, non-cognitive skills programs improve achievement? Discussion Paper 5266, IZA.

McAdams, D. P. (2006). The Person: A New Introduction to Personality Psychology (4 ed.). Hoboken, N.J.: J. Wiley and Sons. 
McArdle, J. J., F. Hamagami, W. Meredith, and K. P. Bradway (2000). Modeling the dynamic hypotheses of Gf-Gc theory using longitudinal life-span data. Learning and Individual Differences 12(1), 53-79.

Means, B. and J. H. Laurence (1984). Characteristics and performance of recruits enlisted with general educational development (ged) credentials. Technical Report FR-PRD-84-6, Human Resources Research Organization, Alexandria, VA.

Michalko, K. T. and D. H. Saklofske (1996). A psychometric investigation of the Wechsler Individual Achievement Test with a sample of Saskatchewan schoolchildren. Canadian Journal of School Psychology 12(1), 44-54.

Mischel, W. (1968). Personality and Assessment. New York: Wiley.

Murray, H. A. (1938). Explorations in personality: a clinical and experimental study of fifty men of college age. New York: Oxford University Press.

National Center for Education Statistics (Various). Digest of Education Statistics. Institute of Education Sciences, U.S. Department of Education. Washington, DC.

Niolon, R. (2005, August). Introduction to the WAIS III. Available at http://www. psychpage.com/learning/library/intell/wais_history.html, posted August, 2005.

Nisbett, R. E. (2009, February). Intelligence and How to Get It: Why Schools and Cultures Count. New York, NY: W. W. Norton and Company.

Nisbett, R. E., J. Aronson, C. Blair, W. Dickens, J. Flynn, D. F. Halpern, and E. Turkheimer (2012, January). Intelligence: New findings and theoretical developments. American Psychologist. January 2, 2012 .

O'Leary, U.-M., K. M. Rusch, and S. J. Guastello (1991). Estimating age-stratified WAISR IQs from scores on the Raven's Standard Progressive Matrices. Journal of Clinical Psychology 47(2), 277-284. 
Omizo, M. M. (1980). The differential aptitude tests as predictors of success in a high school for engineering program. Educational and Psychological Measurement 40(1), 197-203.

R. R. Bowker Publishing (Various). The Bowker Annual: Library and Book Trade Almanac.

Raven, J., J. C. Raven, and J. Court (1988). Manual for Raven's progressive matrices and vocabulary scales. San Antonio, TX: Harcourt Assessment.

Raven, J. C. (1962). Advanced progressive matrices: Sets I and II (Revised ed.). London: H.K. Lewis.

Roberts, B. W. (2009). Back to the future: Personality and assessment and personality development. Journal of Research in Personality 43(2), 137-145.

Roberts, B. W., N. R. Kuncel, R. L. Shiner, A. Caspi, and L. R. Goldberg (2007, December). The power of personality: The comparative validity of personality traits, socioeconomic status, and cognitive ability for predicting important life outcomes. Perspectives in Psychological Science 2(4), 313-345.

Roberts, B. W. and D. Mroczek (2008). Personality trait change in adulthood. Current Directions in Psychological Science 17(1), 31-35.

Roberts, B. W., K. E. Walton, and W. Viechtbauer (2006). Patterns of mean-level change in personality traits across the life course: A meta-analysis of longitudinal studies. Psychological Bulletin 132(1), 1-25.

Roberts, R. D., G. N. Goff, F. Anjoul, P. C. Kyllonen, G. Pallier, and L. Stankov (2000). The Armed Services Vocational Aptitude Battery (ASVAB): Little more than acculturated learning (Gc)!? Learning and Individual Differences 12(1), 81-103.

Rosenberg, M. (1965). Society and the Adolescent Self-Image. Princeton, NJ: Princeton University Press. 
Rothlisberg, B. (1987). Comparing the Stanford-Binet, fourth edition to the WISC-R: A concurrent validity study. Journal of School Psychology 25(2), 193-196.

Rotter, J. B. (1966). Generalized Expectancies for Internal versus External Control of Reinforcement. Washington DC: American Psychological Association.

Rueda, M. R., M. K. Rothbart, B. D. McCandliss, L. Saccomanno, and M. I. Posner (2005). Training, maturation, and genetic influences on the development of executive attention. Proceedings of the National Academy of Sciences 102(41), 14931-14936.

Rutter, M. (2006). Implications of resilience concepts for scientific understanding. Annals of the New York Academy of Sciences 1094(1), 1-12.

Samuel, D. B. and T. A. Widiger (2008). A meta-analytic review of the relationships between the five-factor model and DSM-IV-TR personality disorders: A facet level analysis. Clinical Psychology Review 28(8), 1326-1342.

Savelyev, P. (2011). Conscientiousness, education, and longevity of high-ability individuals. Unpublished manuscript, University of Chicago, Department of Economics.

Schmidt, F. L. and J. Hunter (2004). General mental ability in the world of work: Occupational attainment and job performance. Journal of Personality and Social Psychology $86(1), 162-173$.

Segal, C. (2008, October). Motivation, test scores, and economic success. Economics working papers, Department of Economics and Business, Universitat Pompeu Fabra, Barcelona, Spain.

Social and Character Development Research Consortium (2010, October). Efficacy of schoolwide programs to promote social and character development and reduce problem behavior in elementary school children. Research Report NCER 20112001, National Center for Education Research, Institute of Education Sciences, U.S. Department of Education. 
Stevens, C., J. Fanning, D. Coch, L. Sanders, and H. Neville (2008). Neural mechanisms of selective auditory attention are enhanced by computerized training: Electrophysiological evidence from language-impaired and typically developing children. Brain Research 1205, $55-69$.

Sylva, K. (1997). The quest for quality in curriculum. In L. J. Schweinhart and D. P. Weikart (Eds.), Lasting Differences: The High/Scope Preschool Curriculum Comparison Study through Age 23, pp. 89-93. Ypsilanti: High/Scope Press.

Terman, L. M., B. T. Baldwin, E. Bronson, J. C. DeVoss, F. Fuller, T. Lee Kelley, M. Lima, H. Marshall, A. H. Moore, A. S. Raubenheimer, G. M. Ruch, R. L. Willoughby, J. Benson Wyman, and D. Hazeltine Yates (1925). Genetic Studies of Genius: Mental and Physical Traits of a Thousand Gifted Children, Volume 1. Stanford University, CA: Stanford University Press.

Terman, L. M. and M. A. Merrill (1960). Stanford-Binet Intelligence Scale: Manual for the Third Revision Form L-M. Boston: Houghton Mifflin.

Terman, L. M., M. H. Oden, N. Bayley, H. Marshall, Q. McNemar, and E. B. Sullivan (1947). Genetic Studies of Genius: The Gifted Child Grows Up: Twenty-Five Years' Follow-Up of a Superior Group, Volume 4. Stanford University, CA: Stanford University Press.

Thaler, R. H. (2008, July). A short course in behavioral economics. Edge Master Class, Sonoma, CA, July 25-27, 2008. 